\title{
Base Isolation for Seismic Retrofitting of a Multiple Building Structure: Evaluation of Equivalent Linearization Method
}

\author{
Massimiliano Ferraioli and Alberto Mandara \\ Department of Civil Engineering, Design, Building and Environment, Second University of Naples, Via Roma 29, 81031 Aversa, Italy \\ Correspondence should be addressed to Massimiliano Ferraioli; massimiliano.ferraioli@unina2.it
}

Received 22 April 2016; Revised 21 July 2016; Accepted 17 October 2016

Academic Editor: Alessandro Palmeri

Copyright (C) 2016 M. Ferraioli and A. Mandara. This is an open access article distributed under the Creative Commons Attribution License, which permits unrestricted use, distribution, and reproduction in any medium, provided the original work is properly cited.

\begin{abstract}
Although the most commonly used isolation systems exhibit nonlinear inelastic behaviour, the equivalent linear elastic analysis is commonly used in the design and assessment of seismic-isolated structures. The paper investigates if the linear elastic model is suitable for the analysis of a seismically isolated multiple building structure. To this aim, its computed responses were compared with those calculated by nonlinear dynamic analysis. A common base isolation plane connects the isolation bearings supporting the adjacent structures. In this situation, the conventional equivalent linear elastic analysis may have some problems of accuracy because this method is calibrated on single base-isolated structures. Moreover, the torsional characteristics of the combined system are significantly different from those of separate isolated buildings. A number of numerical simulations and parametric studies under earthquake excitations were performed. The accuracy of the dynamic response obtained by the equivalent linear elastic model was calculated by the magnitude of the error with respect to the corresponding response considering the nonlinear behaviour of the isolation system. The maximum displacements at the isolation level, the maximum interstorey drifts, and the peak absolute acceleration were selected as the most important response measures. The influence of mass eccentricity, torsion, and high-modes effects was finally investigated.
\end{abstract}

\section{Introduction}

The most commonly used isolation devices for buildings are lead rubber bearings, high damping rubber bearings, and friction pendulum bearings. Many studies in the literature focused on the performance of isolators, either made of rubber (with or without lead cores) or based on sliding surfaces (single, double, or triple) [1-4]. These seismic isolation devices are characterized by a nonlinear inelastic behaviour with high initial stiffness for minor horizontal loads and high hysteretic energy dissipation during cycles of loading and unloading. Thus, the behaviour of base-isolated buildings under seismic loading is, in general, both dynamic and nonlinear. However, the nonlinearity is generally confined in the isolation bearings. In fact, the design of isolated structures is carried out so that the isolation system is stable and capable of sustaining forces and displacements associated with maximum considered earthquake ground motions. The structure above the isolation system shall remain essentially elastic since excessively large drifts could result due to the nature of long-period vibration. According to the current code provisions, the analysis of a seismically isolated building with an expected inelastic behaviour of the superstructure may be carried out using two alternative analysis methods: nonlinear time-history analysis (NLTHA) and nonlinear static analysis (Pushover). FEMA 356 [5] admits using the pushover analysis also for base-isolated buildings. The New US building design codes chiefly use this analysis method as a tool to check existing buildings, while both the Eurocode 8 [6] and the Italian Seismic Code [7] do not mention any nonlinear static procedure for the design of base-isolated buildings. Especially for low-rise buildings, the inelastic behaviour of the superstructure has a small impact on the maximum seismic response, and the hysteretic damping and the energy dissipation capacity are controlled by the isolation system. Thus, the analysis of the seismically isolated building is usually carried out neglecting the inelastic behaviour of the superstructure. Moreover, under certain conditions prescribed in many codes, the force-deformation relationship of the isolation system may be defined assuming an equivalent 
linear viscoelastic model. Thus, the linear (static or dynamic) analysis is carried out, at least at the preliminary design and analysis phases. This means that the structure moves as a rigid body, the distribution of the inertia forces is considered to be almost uniform, and the higher oscillation modes are ignored. The approximate linear methods were generally assessed based on a large number of numerical simulations that are generally performed on simplified ideal systems [8-10] while their application to real 3D complex models is still lacking. Moreover, the linear dynamic analysis is in general expected to be limited in its ability to capture the influence of higher modes on the overall response only when using highly nonlinear isolation system while it is considered adequate for isolation system satisfying the limited conditions of equivalent linearization commonly suggested in seismic standards and codes. In this paper, the accuracy of the equivalent linearization was evaluated when applied to a 3D complex model of a multiple building structure with a full representation of bidirectional loading and torsional response. The isolation system meets all the conditions to be considered as being equivalent to linear according to both Eurocode 8 [6] and the Italian Seismic Code [7]. The multiple building structure is located in the hospital campus of Avellino (Italy) and is composed of three adjacent five-storey buildings separated to avoid pounding. The three original fixed-base structures were retrofitted creating a common isolation plane at ground level. It may be very interesting to investigate the appropriateness of using equivalent linear analysis methods when applied to this real case study. In fact, the approximate linear methods were generally assessed based on a single base-isolated structure modelled as a singledegree-of-freedom (SDOF) system, while the case study is a multiple building structure that is quite different from a single base-isolated structure. Thus, relevant issues regarding the higher-modes effects on the superstructure, accidental torsional, and poundings effects were discussed.

\section{Equivalent Linearization of Seismic Isolation System}

The use of equivalent linearization is limited by several requirements, which are usually involved in equivalent stiffness, damping ratio, and restoring force. Many methods proposed in the literature are based on equivalent linearization of the system through analytical or empirical formulas for effective lateral stiffness and equivalent damping ratio $[1,8-12]$. The most frequently used is the method originally proposed by Rosenblueth and Herrera [13] and nowadays adopted by several seismic codes $[6,7,14]$. More recently, Matsagar and Jangid [10] studied the influence of isolator characteristics on the response of base-isolated structures. Mavronicola and Komodromos [15] provided an evaluation of equivalent linearized models assessed through parametric studies. Pant et al. [16] studied the accuracy of the equivalent lateral force (ELF) procedure for the analysis and design of seismically isolated structures. In Liu et al. [17, 18] limited conditions specified in the equivalent linearization of seismic isolation system were investigated when subjected to seismic loads. Zordan et al. [8] proposed an improved expression for equivalent linearization of structures supported on lead rubber bearings. According to Eurocode 8 [6] the use of linear dynamic analysis to avoid a large amount of computational time is allowed only when the isolation system may be modelled with equivalent linear (EL) viscoelastic behaviour. The occurrence of this event depends on a number of limitations that should be satisfied in order to allow the usage of equivalent linear elastic analysis. Specifically, the following limited conditions should be met: (a) the effective stiffness of the isolation system is at least $50 \%$ of the effective stiffness at $20 \%$ of design displacement $d_{\mathrm{dc}}$; (b) the effective damping ratio of the isolation system does not exceed $30 \%$; (c) the force-displacement characteristics of the isolation system do not vary by more than $10 \%$ due to the rate of loading or due to the vertical loads; (d) the increase of the restoring force in the isolating system for displacement between $0.5 d_{\mathrm{dc}}$ and $d_{\mathrm{dc}}$ is at least $2.5 \%$ of the total gravity load above the isolating system. The equivalent linearization of nonlinear isolation systems is based on the determination of effective stiffness and the effective viscous damping ratio, in order to represent both the deformation forces and the energy dissipation during earthquake ground motions. In this paper, the method generally suggested in seismic standards and codes $[6,7]$ for estimating equivalent period and the equivalent viscous damping ratio was applied. This formulation is based on the method originally proposed by Rosenblueth and Herrera [13]. The effective stiffness of the isolating system is calculated as the sum of the effective stiffness $k_{\text {eff }}$ of the isolating bearings. The effective stiffness $k_{\text {eff }}$ is expressed as the secant stiffness of the forcedisplacement curve at the maximum displacement, $d$, as follows:

$$
k_{\mathrm{eff}}=k \cdot \frac{1+\gamma(\mu-1)}{\mu},
$$

where $k=F_{y} / d_{y}$ is the elastic stiffness, $\mu=d / d_{y}$ is the displacement ductility ratio defined as the ratio of the maximum inelastic displacement to the yield displacement, and $\gamma$ is the post-to-pre yield stiffness ratio. The energy dissipation in bearings is evaluated from the measured energy dissipated in cycles with frequency in the range of the natural frequencies of the modes considered and expressed in terms of an equivalent viscous damping (effective damping $\xi_{\text {eff }}$ ). The effective hysteretic damping ratio, $\xi_{\text {eff }}$, of a linear elastic isolation is characterized according to the equal energy dissipation principle, as follows:

$$
\xi_{\mathrm{eff}}=\frac{E_{H}}{4 \pi E_{S}}=\frac{4 F_{y}\left(d-d_{y}\right)}{2 \pi k_{\mathrm{eff}} d^{2}},
$$

where $F_{y}$ is the characteristic strength of the isolator. The effective stiffness and viscous damping ratio of the isolation system were calculated with reference to the design displacement that is determined according to the design earthquake. Since the effective stiffness and the effective damping depend, in general, on the maximum displacement of the isolation bearing, an iterative procedure was applied until the difference between assumed and calculated values of $d$ does not exceed $5 \%$ of the assumed value. 


\section{Dynamic Analysis Procedures}

The seismic response of base-isolated buildings is generally evaluated using three different linear methods: (1) simplified linear static analysis (LSA), (2) response spectrum analysis (RSA), and (3) response history analysis (RHA). The simplified linear analysis method assumes that the superstructure is a rigid solid translating above the isolating system and superimposes static torsional effects. The response spectrum analysis takes into account the total eccentricity of the mass of the superstructure and considers both the horizontal displacements and the torsional movement about the vertical axis. Different damping ratios were considered during analysis: $\xi=15 \%$ for the three lower mode shapes that are dominated by the isolation system; $\xi=5 \%$ for the higher mode shapes that are dominated by the superstructure. The main sources of inaccuracy in the practical application of the RSA for base-isolated buildings are the response spectrum for different viscous damping ratios and the combination rule for nonconventional structures. In fact, the damping correction factor (DCF), even though largely applied in the current state of practice (e.g., the $\eta$-factor in Eurocode 8 [6] and Italian Code [7]), may provide inaccurate predictions for seismically isolated buildings $[19,20]$. Moreover, the square root of sum of squares rule neglects the statistical correlation between modes of vibration. Thus, it may lead to unacceptable inaccuracies when the modal frequencies of the structure are close to each other (e.g., in the first three rigid-body modes for base-isolated buildings). In order to overcome these problems, Muscolino et al. [21] proposed an improved Response Spectrum Method based on a two-stage transformation of coordinates in parallel with a DampingAdjusted Combination (DAC) rule. As far as the response history analysis is concerned, it must be observed that the baseisolated structures are typically nonlinear and nonclassically damped systems. Thus, the standard linear modal analysis based on a linear relationship between damping, mass, and stiffness and modal uncoupling cannot be applied. Thus, as an alternative to direct integration methods, the dynamic equilibrium equation may be uncoupled in the complex modal space (exact complex-valued modal analysis) [22]. This approach can give several advantages for the evaluation of seismic response, and it was found competitive in terms of computational effort with direct integration methods. In general, the response history analysis may be carried out with methods for directly integrating the governing nonlinear equations of motion. The nonlinear behaviour under seismic loading generally takes place only in the isolation bearings. In fact, the base isolation is a way of mitigating the seismic demand on the structure, and thus the superstructure should behave elastically or almost rigid. Thus, the nonlinearity is generally confined to the isolators and is relatively well known. Because of the nonlinearity present in the structural systems, the time domain method should be employed, although it is more time consuming if compared with frequency domain method. As an alternative, FEMA 356 [5] and UBC 97 [23] tolerate the use of nonlinear static procedures (pushover) also for the seismic analysis of isolated structures. On the contrary, both Eurocode 8 [6] and Italian Seismic
Code [7] allow applying this procedure only for fixed-base structures. Therefore, the nonlinear time-history analysis (NLTHA) of base-isolated structures is not uncommon, even though it requires the modelling of the constitutive laws of the devices that are able to adequately reproduce the behaviour of the system in the range of deformations and velocities anticipated in the seismic design situation. This approach requires the solution of a system of nonlinear differential equations whose size is equal to the total number of degrees of freedom of the structure. However, in the case of isolated structures a very restricted number of points in which nonlinear behaviour takes place when subjected to seismic loading occur. This situation, with all nonlinearities restricted to the link elements, allows the application of a simplified nonlinear dynamic procedure for the solution of equilibrium equations: the fast nonlinear analysis (FNA) method [24]. The computational speed of FNA method is very high if compared with the traditional method of nonlinear analysis in which the complete equilibrium equations are formed and solved at each increment of load. Moreover, the use of Ritz vectors allows giving more accurate results than the use of the same number of exact mode shapes. The reason is that the Ritz vectors are generated by taking into account the spatial distribution of the dynamic loading, while the traditional exact mode shapes neglect this information.

\section{Case Study: Hospital Building in Avellino (Italy)}

The case study is a 5-storey hospital building of the new hospital campus of Avellino in Campania (Italy). The construction of the building was never completed, and only the reinforced concrete skeleton structures were erected. The building was composed of three adjacent reinforced concrete frame structures (named A, B, and C) that were linked functionally but structurally disconnected by separation gaps to avoid poundings. The seismic retrofit was carried out by eliminating this separation gap at ground level, thus creating a common isolation plane. The isolation bearings were installed after cutting the bottom portion of the columns under the ground floor. Thus, the three existing reinforced concrete structures were transformed into a single baseisolated multiple building structure (Figures 1 and 2). The isolation system is composed of 25 circular shaped high damping rubber bearings (HDRBs) (with three diameters, namely, 600, 650, and $800 \mathrm{~mm}$ ) and plane surface steel-teflon (PTFE) Sliding Devices (SDs). The plan layout of HDRBs and SDs was selected to minimize the torsion effects due to any eccentricity between the centre of mass of the superstructure and the centre of the rigidity of the isolation system (Figure 3 ). The design displacement was $d_{\mathrm{dc}}=350 \mathrm{~mm}$. The mechanical properties of the isolation rubber bearings used for the sample structure are summarized in Table 1. According to Italian Code [7] and Eurocode 8 [6], the behaviour factor is taken as being equal to $q=1$ for the design of the foundation substructure and the isolation system, $q=1.5$ for the design of the superstructure [25]. The seismic performance evaluation was carried out with the procedure reported in 
TABLE 1: Nominal properties of rubber bearings.

\begin{tabular}{|c|c|c|c|c|c|c|c|c|c|c|c|c|}
\hline Isolator type & $V[\mathrm{kN}]$ & $F_{z d}[\mathrm{kN}]$ & $K_{e}[\mathrm{kN} / \mathrm{mm}]$ & $K_{v}[\mathrm{kN} / \mathrm{mm}]$ & $D_{g}[\mathrm{~mm}]$ & $t_{e}[\mathrm{~mm}]$ & $h[\mathrm{~mm}]$ & $H[\mathrm{~mm}]$ & $Z[\mathrm{~mm}]$ & $W[\mathrm{~kg}]$ & $S_{1}$ & $S_{2}$ \\
\hline SI-S 600/168 & 1010 & 5410 & 0.67 & 813 & 600 & 168 & 268 & 318 & 850 & 435 & 18.13 & 3.45 \\
\hline SI-S 650/180 & 1260 & 6260 & 0.74 & 854 & 650 & 180 & 277 & 327 & 700 & 507 & 17.5 & 3.50 \\
\hline SI-S 800/180 & 3400 & 13280 & 1.12 & 1506 & 800 & 180 & 281 & 341 & 850 & 835 & 19.5 & 4.33 \\
\hline
\end{tabular}

$V=$ maximum vertical seismic load, $F_{z d}=$ maximum vertical design load in Ultimate Limit State (ULS), $K_{e}=$ effective lateral stiffness, $K_{v}=$ vertical stiffness, $D_{g}=$ diameter, $t_{e}=$ total rubber thickness, $h=$ total height (not including anchor plates), $H=$ total height (including anchor plates), $Z=$ side length of anchor plates, $W=$ weight without anchor bolts, $S_{1}=$ primary shape factor, and $S_{2}=$ secondary shape factor.

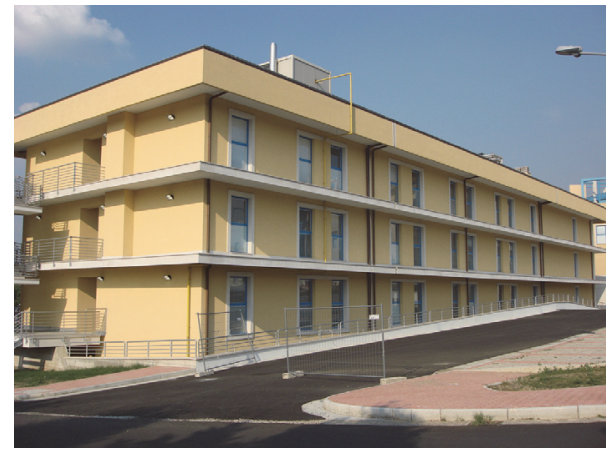

FIGURE 1: View of the hospital building after retrofit.

Annex B of EN 1998-3 [6] and in Italian Code [7]. This procedure is equivalent to the capacity spectrum method based on inelastic demand spectra [26, 27]. The details of the seismic performance evaluation and design process are extensively described in Ferraioli et al. [28, 29].

\section{Numerical Modelling}

5.1. Isolation System. The nonlinear modelling of the isolation devices was carried out using the well-known Bouc-Wen model [30] that has received an increasing interest in the last years due to its capability to represent a wide range of shapes of hysteretic cycles, also including high damping rubber bearings. Through appropriate selections of parameters, this model was used to represent a wide variety of hysteretic behaviour, including softening, hardening pinching, and stiffness/strength degradation. The hysteretic restoring force was approximated by the following expression:

$$
F(x, \dot{x})=\gamma \cdot k \cdot x(t)+(1-\gamma) \cdot k \cdot z(t),
$$

where the extra state variable $z(t)$ satisfies the following differential equation:

$$
\begin{aligned}
\dot{z}(t)= & A \cdot \dot{x}(t)-\alpha \cdot|\dot{x}(t)| \cdot z(t) \cdot|z(t)|^{\eta-1}-\beta \cdot \dot{x}(t) \\
& \cdot|z(t)|^{\eta} .
\end{aligned}
$$

In (3) and (4), $k=F_{y} / d_{y}$ is the elastic stiffness, $\gamma$ is the postto-pre yielding stiffness ratio, $\eta$ is a parameter governing the transition from elastic to plastic response, $A$ and $\alpha / \beta=\psi$ control the loading and unloading phases, and $[A /(\alpha+\beta)]^{1 / \eta}$ regulates the maximum value of the restoring force. Many identification procedures were proposed in the literature to choose the parameters contained in the first-order nonlinear differential equations of this model [31, 32]. In this paper, the procedure proposed by Ferraioli and Malangone [33] was applied. The mechanical parameters of the Bouc-Wen model were adjusted so that the output of the model matches the experimental data. To this aim, the force-displacement results from experimental dynamic tests available for different frequency of loading and compression loads were used. In Figure 4(a) the typical force versus displacement curves for dynamic tests performed on high damping laminated rubber bearings are plotted. The first step in tuning the model is based on the following conditions (Figure 4(b)): (1) the theoretical force-deflection curve shall cross the points where the experimental curve intersects the $y$-axis; (2) the theoretical and experimental values of postelastic stiffness must be coincident. Once these conditions were applied, the model tuning is characterized minimizing the difference between measured and estimated data. The dynamic tests are based on a series of imposed sinusoidal lateral displacement history:

$$
x(t)=d \cdot \sin (\omega \cdot t),
$$

where $d$ is the maximum displacement and $\omega$ is the angular frequency of loading. At the time $t_{p}$ when $x\left(t_{p}\right)=0$ and $F\left(t_{p}\right)=F_{0}$ (Condition 1) the slope of force-displacement curve by model is equal to postelastic stiffness by test (Condition 2): that is, $d F\left(t_{p}\right) / d x=\gamma k$. This equation together with (3) gives

$$
\begin{aligned}
\dot{z}\left(t_{p}\right) & =0, \\
\gamma & =1-\frac{F_{0}}{F_{y}} .
\end{aligned}
$$

Substituting (6)-(7) in (4) gives, after some calculation, the following relation:

$$
\left(\frac{A}{\alpha+\beta}\right)^{1 / \eta}=\frac{F_{0}}{(1-\gamma) \cdot F_{y}}=1 \Longrightarrow A=\alpha+\beta .
$$

Using (7) and (8), only three free parameters remain to be characterized: $\eta$ governing the transition from elastic to plastic response and $\alpha$ and $\beta$ controlling the loading and unloading phases. These parameters were evaluated fitting theoretical predictions and experimental data points. Figure 5 shows the hysteresis model for two isolation rubber bearings: (a) SI-S 650/180; (b) SI-S 800/180. The shear versus transverse displacement relationship is plotted under a sinusoidal displacement history at the design displacement $d_{\mathrm{dc}}$. 


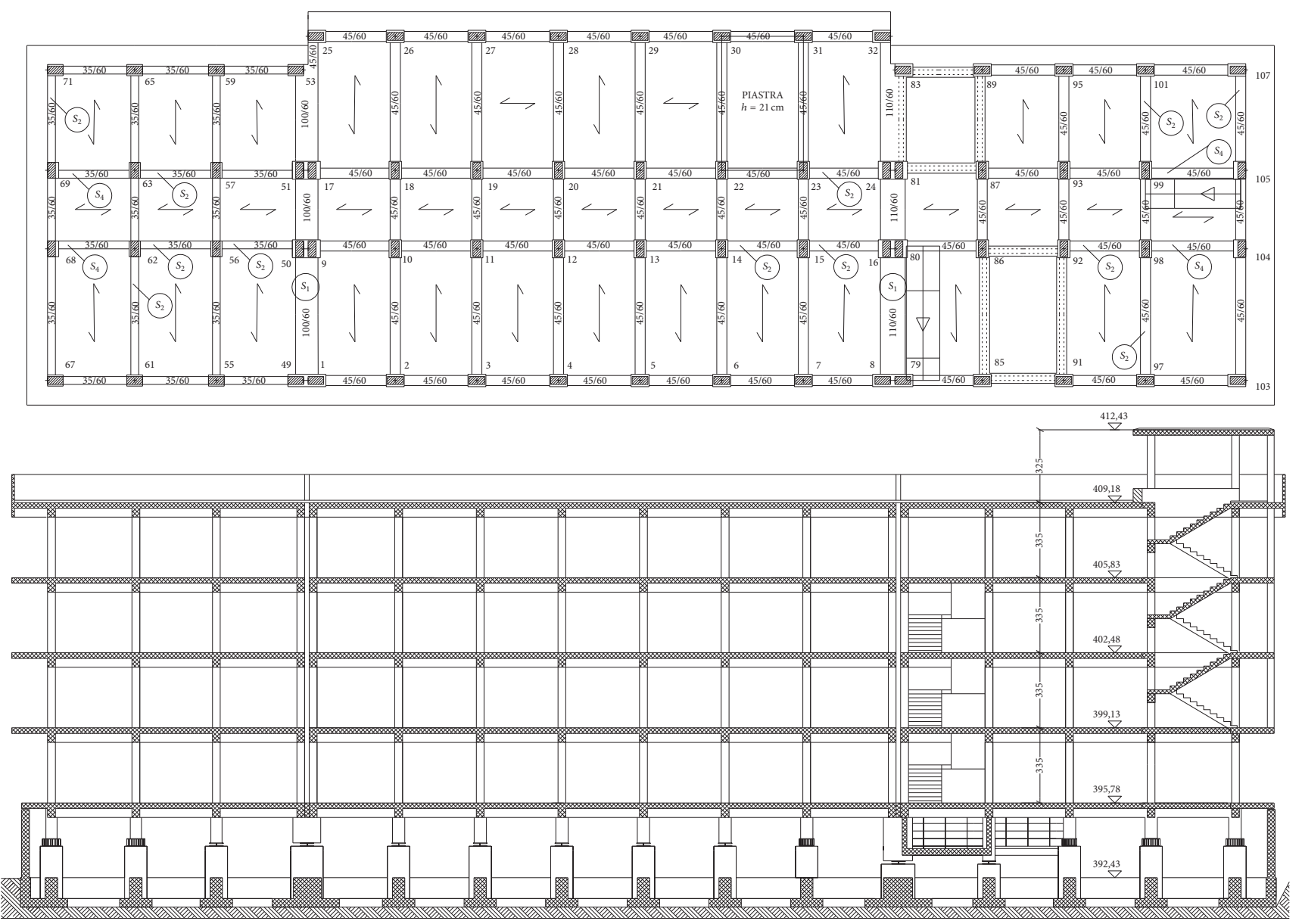

FIgUre 2: Plan and section view of the hospital building after retrofit.

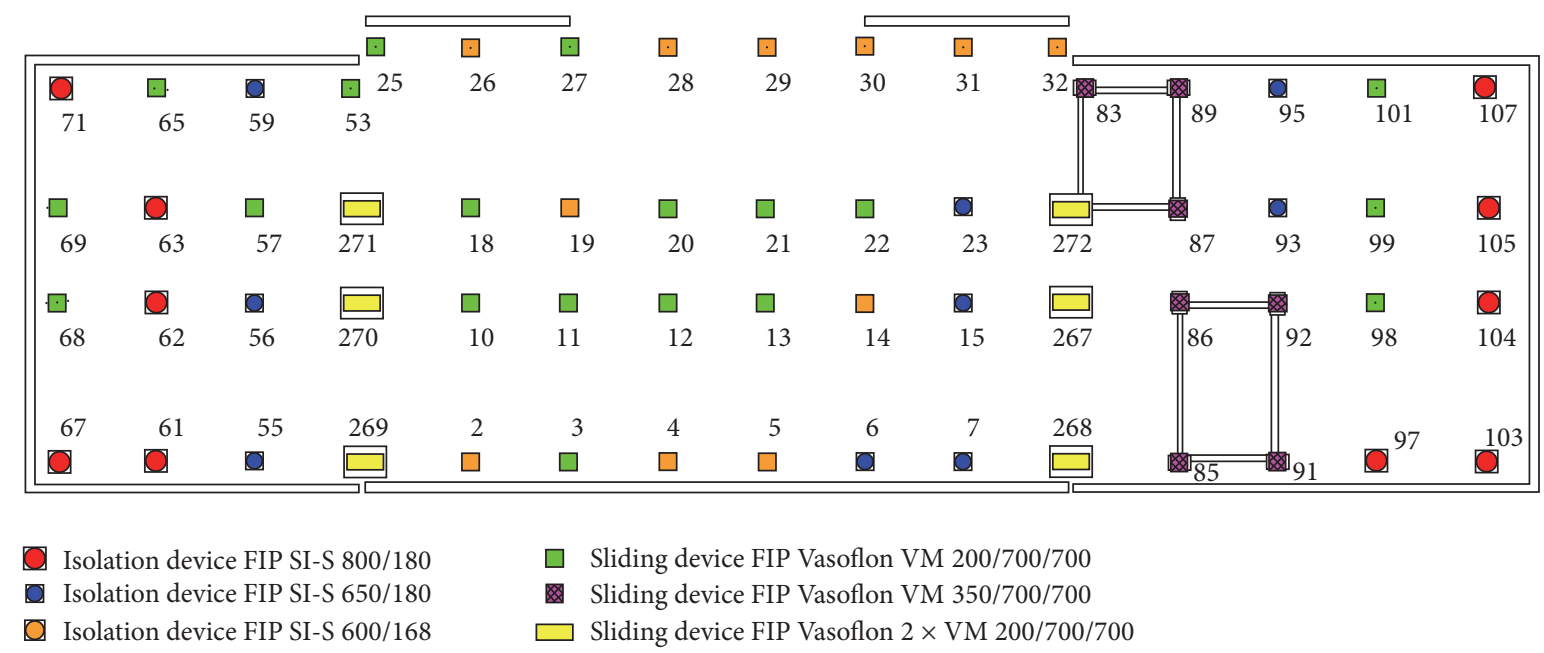

FIgURE 3: Plan layout of the isolation bearings.

5.2. Superstructure. The base-isolated buildings are designed such that the superstructure remains elastic and the nonlinearities are localized at the isolation level. Thus, the superstructure is generally modelled by a linear elastic system, and the nonlinear behaviour is restricted to the base isolation bearings. However, the case study is a multiple building structure for which the influence of higher modes on the overall nonlinear response could be significant. Hence, both a linear and a nonlinear model were considered for the superstructure in order to evaluate if it remains elastic or 


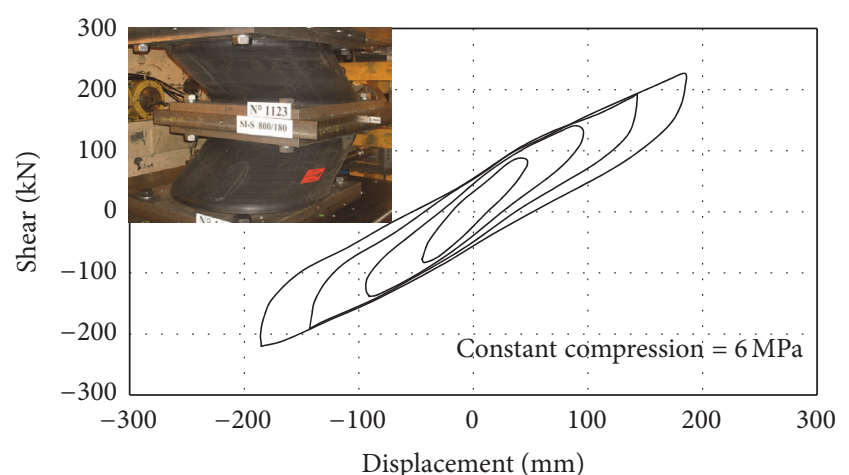

(a)

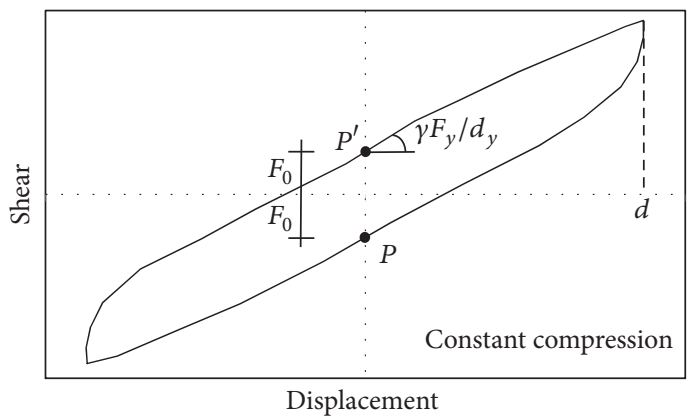

(b)

FIGURE 4: (a) Shear versus transverse displacement relationship (seismic isolator SI-S 800/180). Sinusoidal displacement history. Loading frequency $=0.5 \mathrm{~Hz}$. (b) Identification of mechanical parameters.

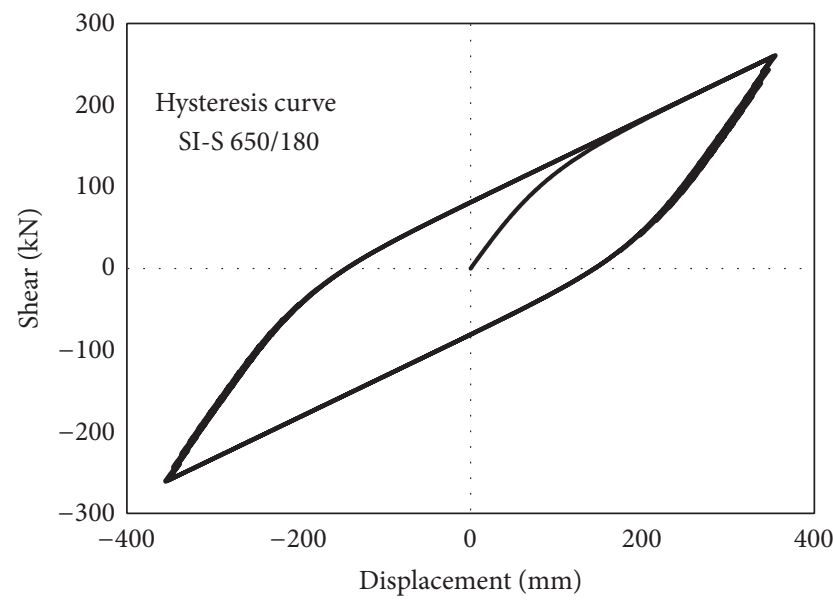

(a)

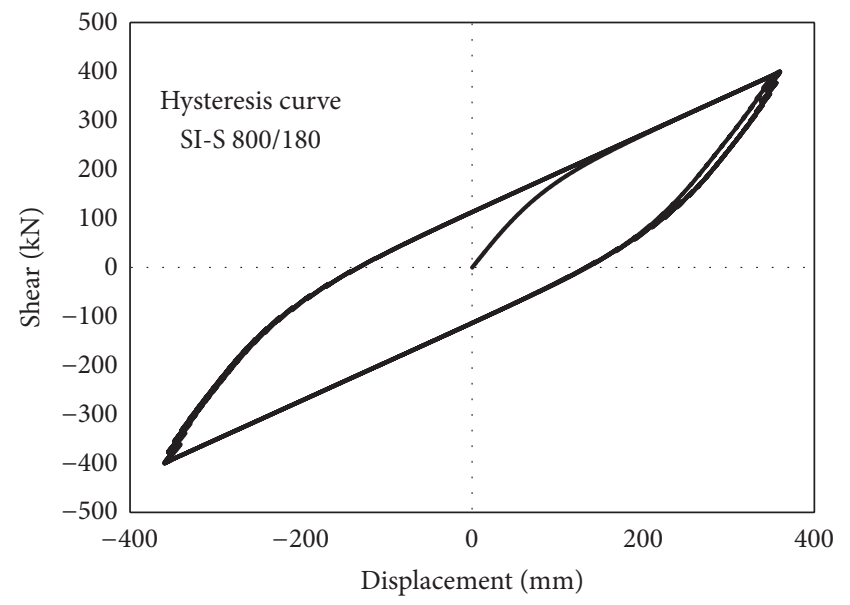

(b)

FIGURE 5: Hysteresis model for two isolation bearings: (a) SI-S 650/180; (b) SI-S 800/180.

nearly elastic. A three-dimensional finite element model was implemented in SAP 2000 computer program [34]. The floor diaphragms were considered as being rigid in their planes since they have sufficient in-plane stiffness. This hypothesis was justified according to the Italian Code [7] and Eurocode 8 [6] provisions. To this aim, two analysis were carried out, one neglecting and the other considering the diaphragm in-plane flexibility. The diaphragm was considered as rigid because the diaphragm flexibility nowhere increases the horizontal displacements by more than $10 \%$. The high stiffness and strength of the foundation allowed the foundation-structure interaction to be neglected. Both columns and beams were modelled using two-node beam elements with 6 degrees of freedom at each node. Shear walls were modelled as shell elements. The isolators were modelled using link element, which is a two-node element connected by six springs. Each node has six degrees of freedom. The finite element model is composed of 2281 nodes, 1439 beam elements, 1892 shell elements, and 62 link elements (Figure 6). In this paper, both linear and nonlinear analyses were performed. A fiber plastic hinge model for the members of the framed structures was used to simulate the interaction among bidirectional bending moments and axial load. This model is more natural, but also more computationally expensive than the coupled PMM hinge model, since it automatically accounts for interaction, changing moment-rotation curve, and plastic axial strain. Each fiber of the cross-section was modelled with the nonlinear stress-strain relationship of the material it was made from: confined concrete for the core, unconfined concrete for the cover, and steel for the longitudinal bars. The stress-strain model originally proposed by Mander et al. [35] was used for the confined concrete incorporating the relevant parameters of confinement (section geometry, concrete strength, type and arrangement of transverse reinforcement, its volumetric ratio, spacing, and yield strength). Confinement factors were evaluated according to Eurocode 8 [6] and varied along the member length according to the arrangement of the transverse reinforcements. Steel was modelled with an elasticplastic-hardening relationship. Since the existing structures were designed according to seismic design provisions, the shear capacity was sufficiently high to avoid the undesirable formation of a plastic hinge inside the joint. Thus, the rigid 


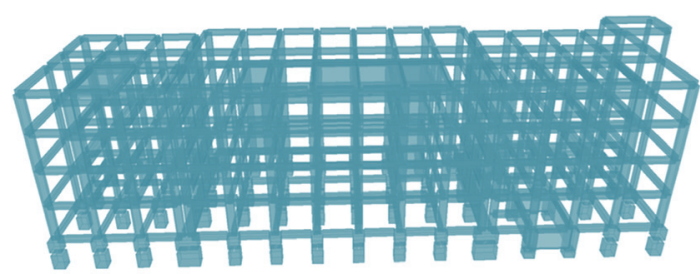

FIgURE 6: Three-dimensional finite element model of the baseisolated multiple building structure.

elements were placed at beam-column connections to prevent the formation of plastic hinges inside the connections. The rigid zones have horizontal dimensions equal to the column cross-sectional dimensions and vertical dimension equal to the beam depth. Gaps between centre lines of beams and columns were considered in the modelling of the beamcolumn connection. Rigid elements were used to connect the centre lines of the beams and columns in order to model the force transfer between the members and torsion due to gaps between the centre lines of the members. The length of plastic hinge was estimated by formula A.5 from EN 1998-3 [6]:

$$
L_{\mathrm{pl}}=0.10 L_{V}+0.17 h+0.24 \frac{d_{b L} f_{y}(\mathrm{MPa})}{\sqrt{f_{c}}(\mathrm{MPa})},
$$

where $L_{V}$ is the shear span (ratio $M / V$ moment/shear at the end section), $h$ is the depth of the member, and $d_{b L}$ is the mean diameter of the tension reinforcement.

The isolation bearings were modelled with the Wen plasticity property type implemented in SAP2000 [34] for uniaxial deformation, which is equivalent to Wen model [30] with $A=1$ and $\alpha=\beta=0.50$. In the same way, the deformability of the foundation may be neglected in the model when compared to the flexibility of isolation system. The design gravity loads were used in modelling. The permanent gravity loads are $4.00 \mathrm{kN} / \mathrm{m}^{2}$ for the top floor and $5.80 \mathrm{kN} / \mathrm{m}^{2}$ for the other floors. The values of the imposed loads are $1.00 \mathrm{kN} / \mathrm{m}^{2}$ for the top floor and $3.00 \mathrm{kN} / \mathrm{m}^{2}$ for the other floors.

5.3. Input Ground Motions. In the literature, there are three types of acceleration time histories: artificial accelerograms compatible with design response spectrum, synthetic accelerograms obtained from seismological models, and real earthquake ground motions. Due to the increase of available strong ground motion databases, real recorded accelerograms have become the most common input for the response history analysis [36-38]. Another important advantage is that the recorded accelerograms allow accounting for characteristics like frequency, duration, and energy of real earthquake ground motions. Thus, the selection of real earthquake records has become a frequently applied tool to assess the structural performance. Currently, a great number of methods of ground motion record selection and modification are available in the literature [37,39-45]. Selection based on magnitude $M$, distance $R$, and "epsilon" parameter associated with ground motions and selection by target spectrum matching are generally accepted as the most effective methods for ground motion record selection $[42,46]$. Other factors such as the site condition, style-of-faulting, and spectral content may also be considered. However, the selection of ground motion based on $M, R$, and $\varepsilon$ for all the considered intensity measure (IM) levels is not possible. Hence, due to the limited number of recorded ground motions, the scaling of the records to match them with a target response spectrum that is compatible with the different IM levels is necessary. The amount of scaling that can be applied is a controversial topic. Current design and evaluation methodologies suggest intensity-based methods to scale record over spectral matching techniques that adapt the frequency content of the ground motion to match its response spectrum to the target spectrum. The main goal of these methods is to provide scale factors for a small number of ground motion records so that the RHA of the structure gives accurate estimate in the median value of the demand parameters and is efficient in minimizing their record-torecord variations. Scaling ground motions to match a target value of peak ground acceleration has been the first approach to the problem, which produces inaccurate evaluations with large dispersion in demand parameters. Other intensity measures (effective peak acceleration, Arias intensity, and effective peak velocity) have been found to be inaccurate and inefficient [41]. The most commonly applied ground motion scaling method to meet the requirements of seismological parameters implicates the selection of ground motion records with a mean spectrum close to the target spectrum. This time domain scaling transforms the amplitude of the acceleration without affecting frequency content or phasing. Similar rules for selecting and scaling ground motion records are largely described in current building codes. The ground motion selection and scaling procedures in IBC [47] are based on ASCE 7-05 [48], while in Italian Code [7] they are based on Eurocode 8 [6]. In this paper, the ground motion selection and scaling procedure included in Eurocode 8 [6] was applied. The European Strong-Motion Database (ESD) (http://www.isesd.hi.is) [49] was used for selecting a set of 10 recorded accelerograms. The suite of accelerograms observed the rules recommended in the seismic standards $[6,7]$. The recorded accelerograms are adequately qualified with regard to the soil conditions appropriate to the site, and their values are scaled to the value of $a_{\mathrm{g}} \cdot S$ for the zone under consideration, where $a_{\mathrm{g}}$ is the design ground acceleration on type A ground and $S$ is the soil factor. Moreover, the suite of artificial accelerograms observes the following rules: (1) the mean of the zero period spectral response acceleration values (calculated from the individual time histories) was not smaller than the value of $a_{\mathrm{g}} \cdot S$ for the site in question; (2) in the range of periods between $0.2 T_{\text {ISO }}$ and $1.2 T_{\text {ISO }}$ (where $T_{\text {ISO }}$ is the fundamental period of isolated building) no value of the mean 5\% damping elastic spectrum, calculated from all time histories, was less than $90 \%$ of the corresponding value of the 5\% damping elastic response spectrum for the Life Safety (LS) Limit State (LS). The recorded ground motions considered in the numerical analysis are summarized in 
TABLE 2: Set of earthquake natural records.

\begin{tabular}{|c|c|c|c|c|c|}
\hline Waveform ID & Earthquake name & Date & Direction & PGA $\left[\mathrm{m} / \mathrm{s}^{2}\right]$ & Magnitude $M_{W}$ \\
\hline $181 X$ & Boshroyeh & 16.09 .78 & EW & 1.003 & 7.3 \\
\hline $293 X$ & Rionero in Vulture & 23.11 .80 & EW & 0.968 & 6.9 \\
\hline $302 Y$ & Lauria & 23.11 .80 & NS & 0.155 & 6.9 \\
\hline $335 Y$ & Korinthos & 25.02 .81 & NS & 1.144 & 6.3 \\
\hline $353 Y$ & Balikesir & 05.07 .83 & NS & 0.237 & 6.1 \\
\hline $477 X$ & Tehran & 20.06 .90 & EW & 0.324 & 7.4 \\
\hline $477 Y$ & Tehran & 20.06 .90 & NS & 0.286 & 7.4 \\
\hline $480 Y$ & Tonekabun & 20.06 .90 & NS & 1.341 & 7.4 \\
\hline $499 Y$ & Akhalkalaki & 29.04 .91 & NS & 0.113 & 6.8 \\
\hline $536 X$ & Tercan & 13.03 .92 & EW & 0.286 & 6.6 \\
\hline
\end{tabular}

Table 2. In Figure 7, the spectrum compatibility for the selected acceleration records was represented. Figure 7 gives the pseudo-velocity response spectra (PSV) of the selected earthquake ground motions, their mean and mean \pm standard deviation, and the target spectrum (that is the elastic design response spectrum of Italian Code [7] for the Collapse Prevention Limit State). The same figure shows the spectral pseudo-velocity of the original fixed-base structures (FB-A, FB-B, and FB-C) and the base-isolated building. Finally, it should be noted that, in general, a limit on the amount of scaling should be applied since some aspect of the event that produced the source motion may be inconsistent with the maximum considered earthquake being modelled. Thus, scale factors closer to unity should be preferred. However, the case study is a hospital building located within the high seismic hazard zone. Thus, the reference peak ground acceleration for the construction site corresponding to Life Safety (LS) and Collapse Prevention (CP) Limit States (LS) are very high $\left(a_{\mathrm{g}} / \mathrm{g}=0.318\right.$ for LSLS; $a_{\mathrm{g}} / \mathrm{g}=0.345$ for CPLS). In this case, owing to the limited number of recorded ground motions, the primary selection of compatible records with scale factors closer to unity is not possible. Furthermore, the recommended limits on scaling proposed in the literature $[42,46]$ are not based on quantitative evaluations of scaling. Finally, the scale factors are not limited by the seismic code provisions, and the primary objective of the paper is to evaluate the equivalent linearization method for the analysis of base-isolated multiple building structures according to seismic standards.

\section{Results}

In Figure 8, the roof plan of the first eight mode shapes is plotted. It can be observed that the first three mode shapes are dominated by the isolation system while the other mode shapes are dominated by the superstructure. Table 3 gives the dynamic properties of the isolated structure (modal period, spectral acceleration at various limit states, and modal mass ratios $\alpha_{x}$ and $\alpha_{y}$ ). Figure 9 shows the displacement time-history of the isolation plane calculated for either elastic or inelastic modelling of superstructure. In the same way, in Figure 10, the time-history of the relative displacement between top and bottom of the superstructure

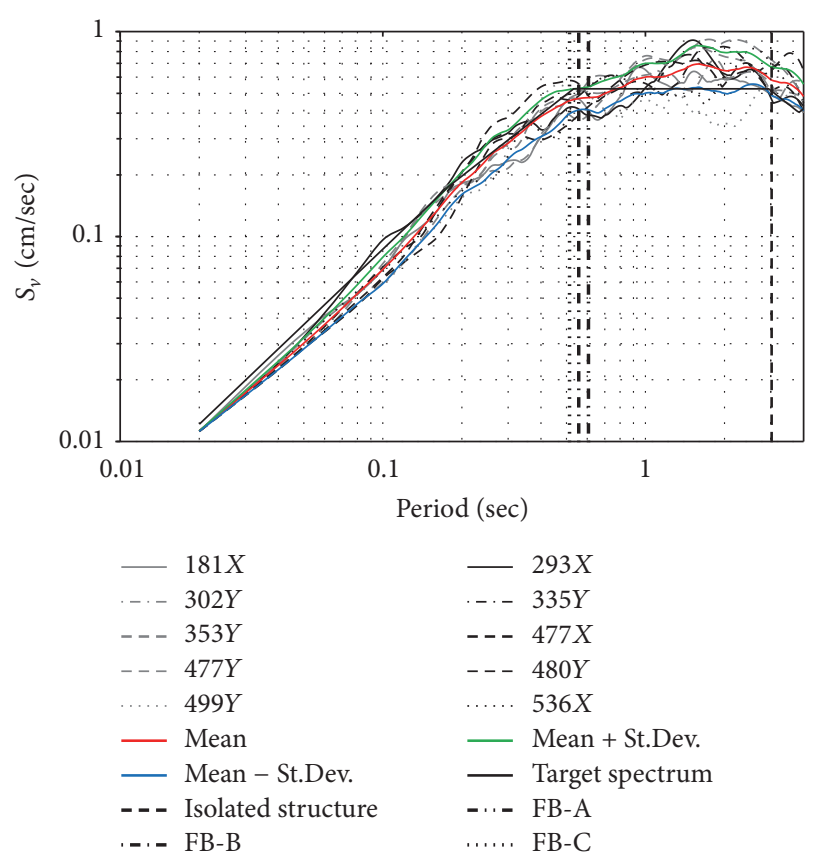

FIGURE 7: Spectrum compatibility for the selected records.

(total drift) is plotted. The results show negligible dependence from inelasticity of the superstructure. This means that the isolation system is effective in reducing the seismic forces and avoiding the yielding of the superstructure. The nonlinear behaviour takes place exclusively in the isolation bearings. Thus, the superstructure was represented with a linear elastic model in the subsequent analyses. Since nonlinearities occur only in a very limited number of points, the response history analysis was carried out with the fast nonlinear analysis (FNA) method [24]. In Figures 11 and 12, the results of FNA and NLRHA are compared. A very good agreement was achieved. The algorithm of nonlinear modal time-history analysis (FNA) was found to be extremely efficient for the sample base-isolated structure that has a limited number of nonlinear elements. Thus, the fast nonlinear analysis (FNA) method was used in the subsequent analyses.

In this paper, the suitability of equivalent linearization (EL) to represent sufficiently well the behaviour of the sample 


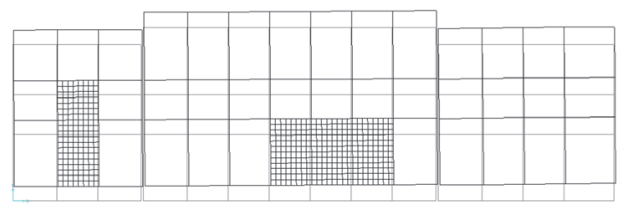

First mode shape: $1^{\circ}$ flexural $Y$ Period $3.020 \mathrm{sec}$

Mode shape dominated by isolation system

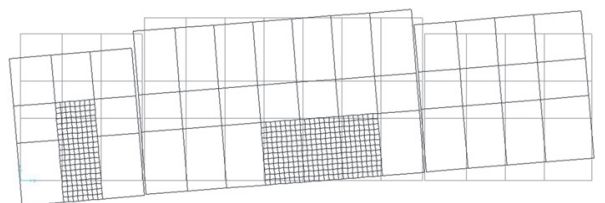

Third mode shape: torsional Period $2.265 \mathrm{sec}$

Mode shape dominated by isolation system

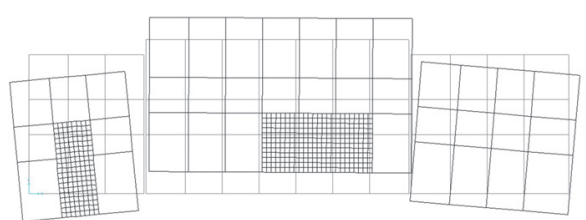

Fifth mode shape: flexural $Y$ Period $0.364 \mathrm{sec}$

Mode shape dominated by superstructure

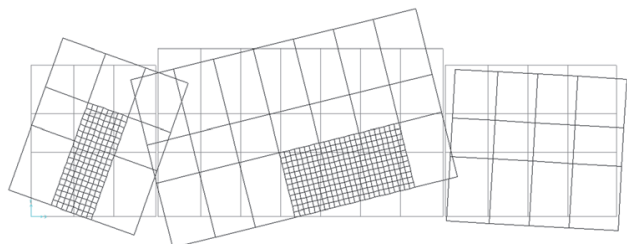

Seventh mode shape: torsional Period $0.323 \mathrm{sec}$

Mode shape dominated by superstructure

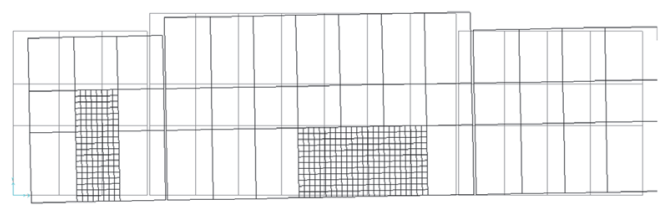

Second mode shape: $1^{\circ}$ flexural $X$ Period $3.014 \mathrm{sec}$

Mode shape dominated by isolation system

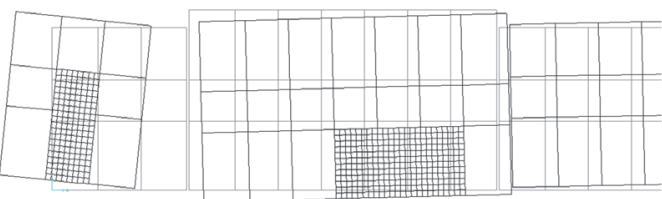

Forth mode shape: flexural $X$ Period $0.367 \mathrm{sec}$

Mode shape dominated by superstructure

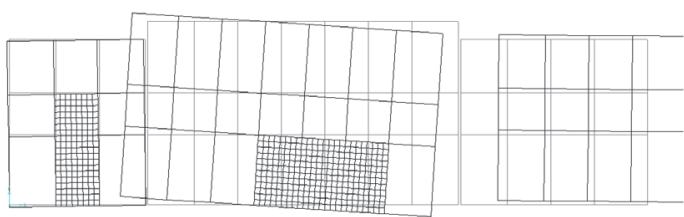

Sixth mode shape: flexural $X$

Period $0.342 \mathrm{sec}$

Mode shape dominated by superstructure

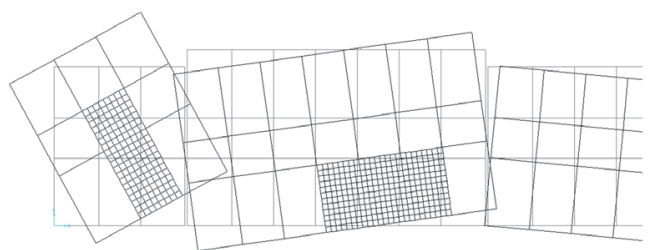

Eighth mode shape: torsional Period $0.320 \mathrm{sec}$

Mode shape dominated by superstructure

Figure 8: First eight mode shapes (roof plan view).

TABLE 3: Dynamic properties of isolated structure.

\begin{tabular}{lcccccccc}
\hline Mode & Period $(\mathrm{sec})$ & $\xi(\%)$ & $\alpha_{x}(\%)$ & $\alpha_{y}(\%)$ & $S_{a} / \mathrm{g}(\mathrm{IO})$ & $S_{a} / \mathrm{g}(\mathrm{DL})$ & $S_{a} / \mathrm{g}(\mathrm{LS})$ & $S_{a} / \mathrm{g}(\mathrm{CP})$ \\
\hline 1 & 3.020 & 15 & 0.00 & 99.98 & 0.032 & 0.044 & 0.100 & 0.112 \\
2 & 3.014 & 15 & 99.99 & 0.00 & 0.032 & 0.044 & 0.100 \\
3 & 2.250 & 15 & 0.00 & 0.01 & 0.056 & 0.078 & 0.198 \\
4 & 0.367 & 5 & 0.00 & 0.00 & 0.307 & 0.392 & 0.853 \\
5 & 0.364 & 5 & 0.00 & 0.00 & 0.307 & 0.392 & 0.853 \\
6 & 0.342 & 5 & 0.00 & 0.00 & 0.307 & 0.392 & 0.853 \\
7 & 0.323 & 5 & 0.00 & 0.00 & 0.307 & 0.392 & 0.907 \\
8 & 0.320 & 5 & 0.00 & 0.00 & 0.307 & 0.392 & 0.907 \\
\hline
\end{tabular}

multiple building structure was investigated. In the case study, the behaviour of the isolation system could be represented by means of equivalent properties (stiffness and damping) computed at a lateral displacement corresponding to the limit state under consideration. In fact, the limited conditions specified in Eurocode 8 [6] for the equivalent linearization of nonlinear isolation systems are met. The modal linear analysis was carried out using the method generally suggested in seismic standards and codes for estimating effective stiffness $\left(k_{\text {eff }}\right)$ and effective damping $\left(\xi_{\text {eff }}\right)$ of the bearing devices ((1) and (2)). The results of the response spectrum analysis (RSA) were compared to those of the nonlinear time-history 


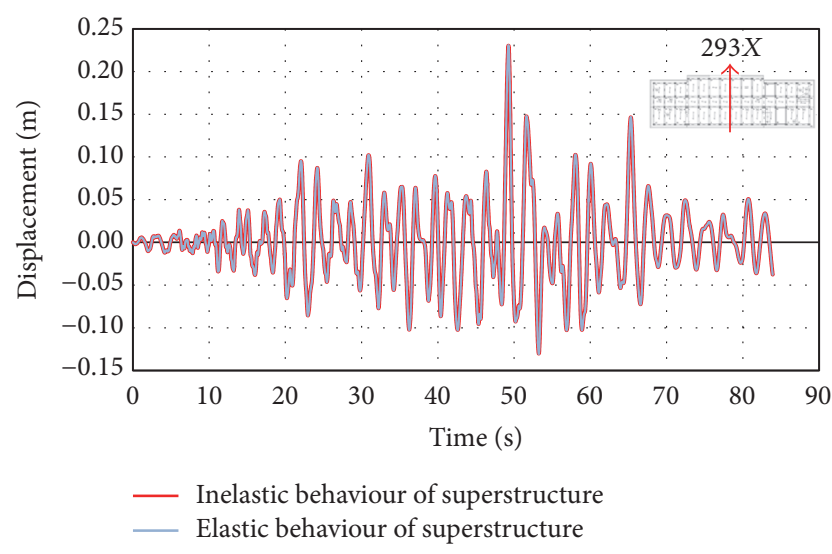

FIgURE 9: Displacement time-history of the isolation plane. Elastic versus inelastic model of superstructure. Waveform N.293X. $y$ direction.

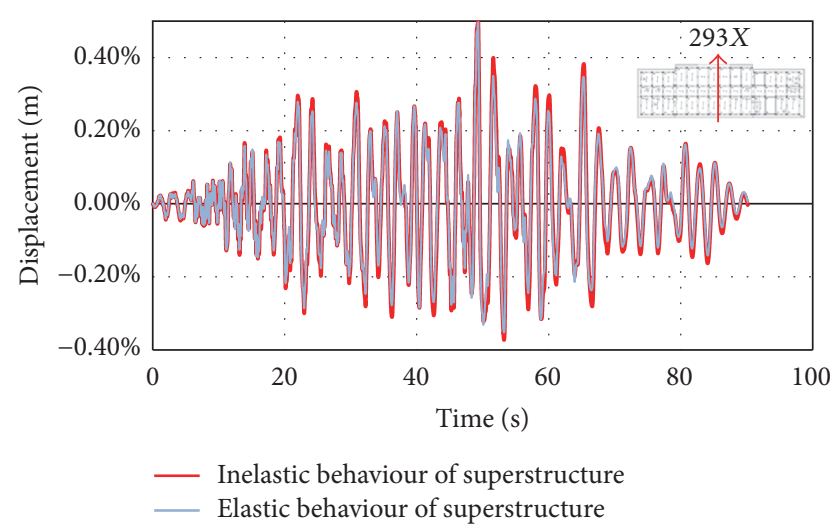

FIGURE 10: Total drift time-history of superstructure. Elastic versus Inelastic model of superstructure. Waveform N.293X. $y$-direction.

analysis (NLTHA). At first, the comparison was carried out using the seismic response parameters derived from the structural analysis (i.e., peak interstorey drifts, maximum floor displacements, and acceleration). In Figure 13, the scatter plot of estimated interstorey drifts is shown. The peak interstorey drifts resulting from response spectrum analysis (RSA) are compared with the peak interstorey drifts resulting from nonlinear response history analysis (NLRHA). Each figure refers to a superstructure $(\mathrm{A}, \mathrm{B}$, and $\mathrm{C})$ and a direction of seismic ground motion $(X / Y)$. The interstorey drift ratios obtained with nonlinear response history analysis (NLRHA) are assumed as reference values ( $x$-axis) and the corresponding values obtained with the response spectrum analysis (RSA) are shown on the $y$-axis. Thus, the points on the graph represent the maximum interstorey drift ratio of each storey in elevation. The bisector represents the cases where RSA presented the same results of NLRHA. The straight lines numbered $-10 \%,-20 \%$, and $-30 \%$ are representative of error

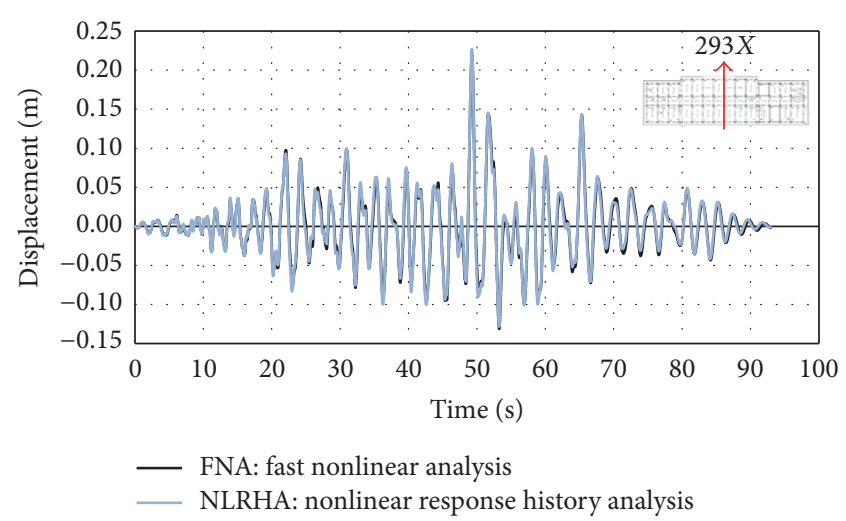

FIGURE 11: Displacement time-history of the isolation plane. FNA versus NLRHA. Waveform N.293X. $y$-direction.

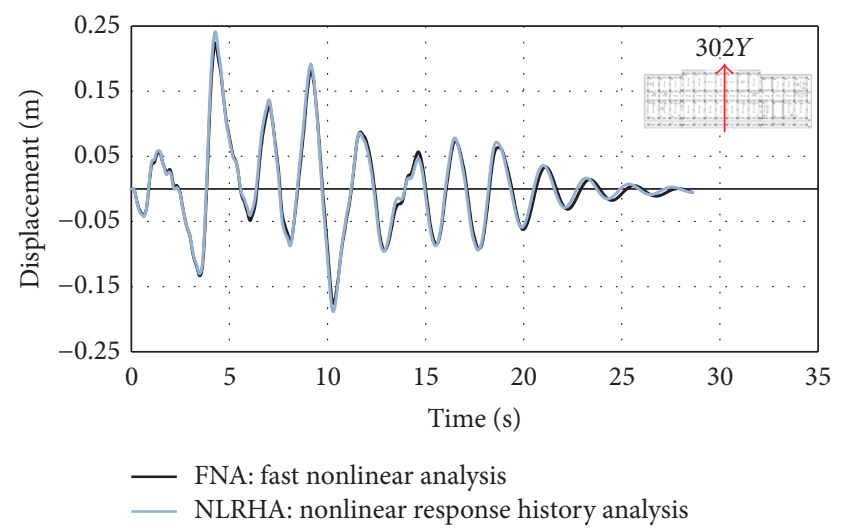

FIGURE 12: Displacement time-history of the isolation plane. FNA versus NLRHA. Waveform N.302Y. $y$-direction.

rates (defined in subsequent (10)) equal to $-10 \%,-20 \%$, and $-30 \%$, respectively,

$$
\operatorname{Error}(\%)=100 \times \frac{\Delta_{k, \mathrm{RSA}}-\Delta_{k, \mathrm{NLRHA}}}{\Delta_{k, \mathrm{NLRHA}}} .
$$

In (10), $\Delta_{k, \mathrm{RSA}}$ is the maximum interstorey drift of $k$ th storey resulting from RSA and $\Delta_{k, \mathrm{NLRHA}}$ is the maximum interstorey drift of $k$ th storey resulting from NLRHA. The graphs of Figure 13 synthesize the consistency between RSA and NLRHA in terms of interstorey drift ratio. When all the points representing the pairs of values are clustered around the bisector, both methods tend to give the same results. On the contrary, when some values lie down of the straight lines numbered $-10 \%$, it means that the error of the interstorey drift coming from RSA with respect to the interstorey drift from NLRHA is greater than $10 \%$. This means that in these cases an underestimation of $10 \%$ is obtained when the RSA procedure is applied. In the same way, when some values lie down of the straight lines numbered $-20 \%$ or $-30 \%$, it means that the corresponding underestimation is greater than $20 \%$ and $30 \%$, respectively. Finally, it is to be observed 

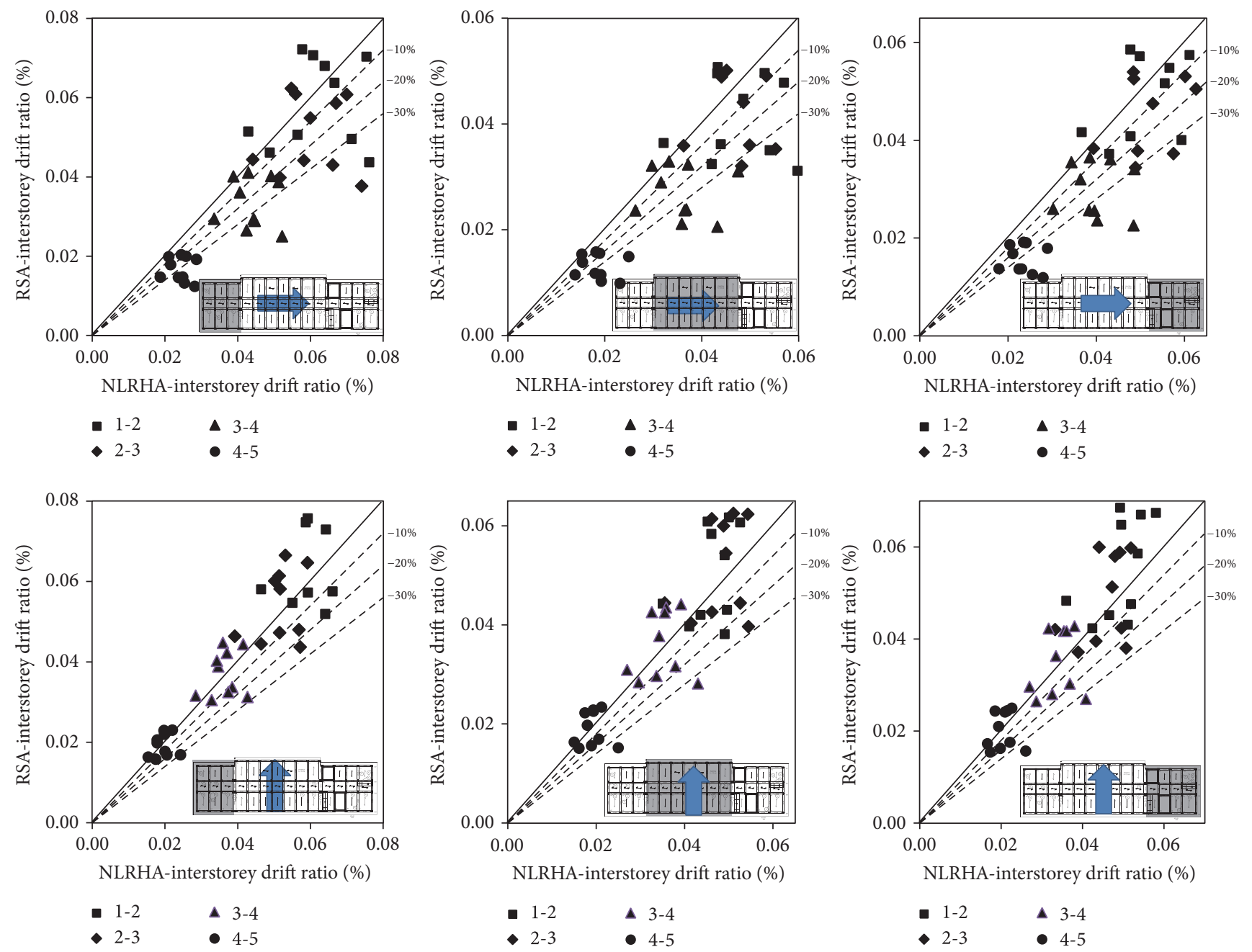

FIGURE 13: Scatter plot of estimated interstorey drift ratio.

that the points over the bisector are situations where the value of interstorey drift ratio from RSA is greater than the corresponding value from NLRHA. In these cases, the RSA gives conservative estimates of the nonlinear dynamic response. The results of Figure 13 show that the RSA may give unconservative estimates of the structural response when compared to NLRHA, especially for seismic action in the $x$ direction (error greater than 30\%). In Figure 14 the scatter plot of the mean values of the maximum interstorey drift values obtained exciting the building with the ten considered records is shown. The mean values resulting from RSA are compared with the mean values from NLRHA. The results show that also the error on the mean value in $x$-direction may be greater than $20 \%$. In Figure 15 the scatter plot of standard deviation resulting from RSA and NLRHA is shown. Results demonstrate a good correlation for seismic action in the $x$-direction. On the contrary, in the $y$-direction, the RSA tends to give a higher standard deviation if compared to NLRHA. The reason is that the multiple building structure has a slenderness ratio in plan (height to base ratio) equal to 3.26. Thus, for seismic action in the $y$-direction, the torsional effects are anyhow significant and the dynamic response is more sensitive to the special characteristics of the input ground motion. In Figure 16, the following scatter plots are shown: (a) maximum base displacement; (b) maximum roof displacement; (c) maximum roof acceleration. The results are obtained for seismic action in $x$ - and $y$-directions. In the same figure the mean values among the set of ground motion records are reported. The comparison of results between RSA and NLRHA shows that the relative error of the mean displacement at the isolation level (base) is $18.6 \%$ in $x$ direction and $23.6 \%$ in $y$-direction. The relative error of the mean displacement at the roof level is $13.7 \%$ in $x$-direction and $18.7 \%$ in $y$-direction. This means that conservative estimates of the lateral displacement were generally obtained. On the contrary, an underestimation greater than $20 \%$ of acceleration in $x$-direction was evidenced. In fact, the relative error of the mean acceleration at the roof level is $-22.9 \%$ in $x$-direction and $-8.9 \%$ in $y$-direction.

The paper also investigated the suitability of the linearized elastic model for the analysis of the accidental torsional effects. The lateral-torsional response of structures was 

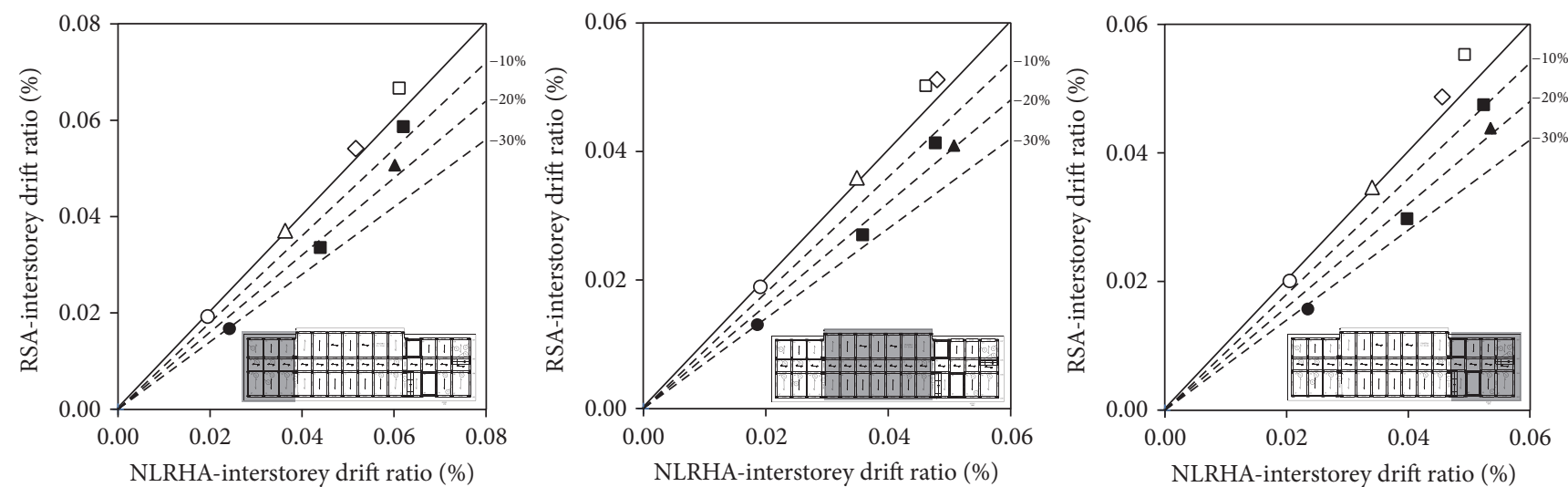

$\begin{array}{ll}\bullet 1-2 X & \diamond 2-3 X \\ \Delta 3-4 X & \bullet 4-5 X \\ \square 1-2 Y & \diamond 2-3 Y \\ \triangle 3-4 Y & \circ 4-5 Y\end{array}$

$\begin{array}{ll}\text { - } 1-2 X & \diamond 2-3 X \\ \triangle 3-4 X & \bullet 4-5 X \\ \square 1-2 Y & \diamond 2-3 Y \\ \triangle 3-4 Y & \circ 4-5 Y\end{array}$
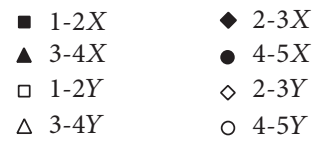

FIGURE 14: Scatter plot of estimated interstorey drift ratio (mean value).
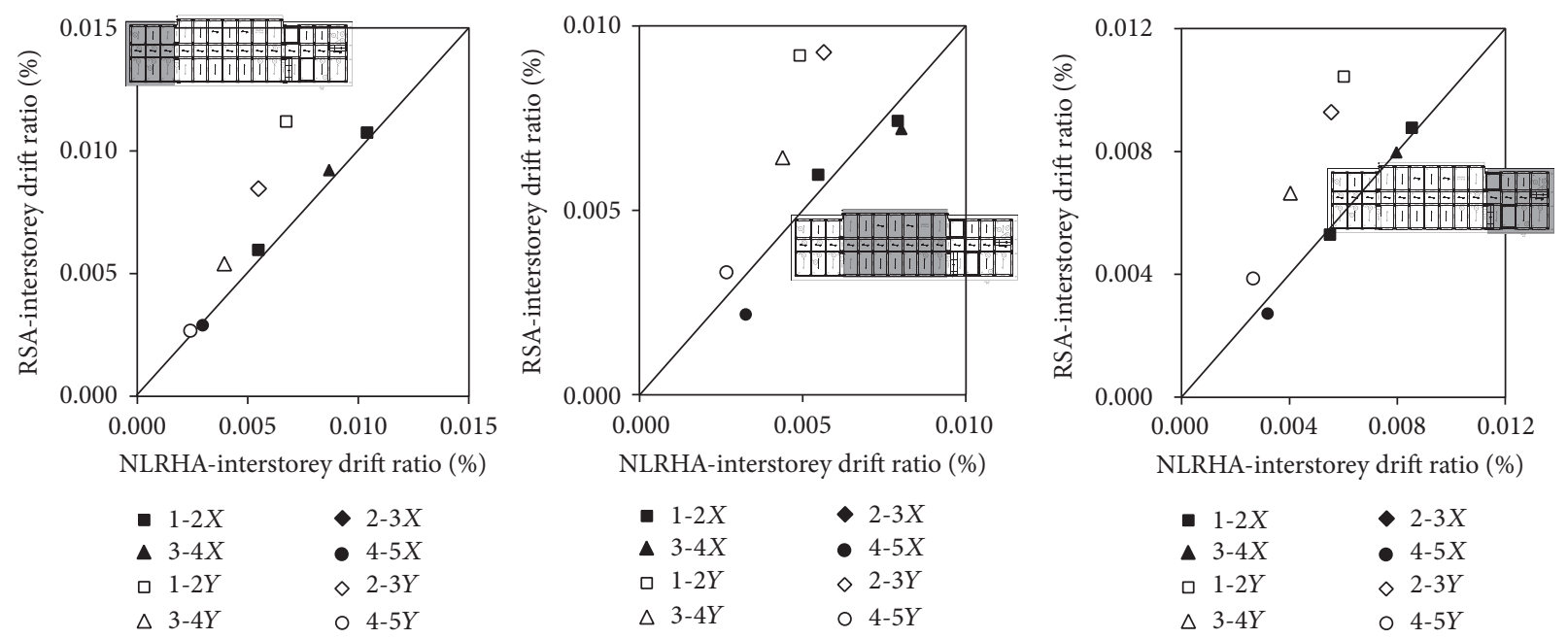

FIGURE 15: Scatter plot of estimated interstorey drift ratio (standard deviation).

extensively studied in the literature [51-54]. Although the magnitude of shear and torque generated in an elastomeric isolated structure is generally less than that of the fixed-base structure, in general, the torsional amplifications cannot be ignored. In fact, the eccentricity of the centre of mass on the isolation plane may increase the lateral displacement of the isolation devices. In particular, torsion leads to significantly increased isolator deformations especially if large rotations and large lateral deformations at the centre of mass occur at or very near the same time during the earthquake. The main source of torsional motions in seismically isolated buildings is the eccentricity between the centre of the stiffness of the isolation system and the centre of mass of the structure. In order to deal with these torsional effects, an accidental eccentricity is used by standards to displace the mass in every floor. The centre of mass is shifted creating an eccentricity $e / L=$ \pm 0.05 (where $L$ is the floor-dimension perpendicular to the direction of the seismic action) that is the worldwide assumed code value for multistorey buildings. It is to be observed that the case study is a multiple building structure. Each floor is composed of three floor diaphragms disconnected by seismic separation gaps. Hence, the accidental eccentricity was taken into account acting to the mass multipliers so to create the required additional torsional actions. The consistency between RSA and NLRHA was evaluated using the following displacement error:

$$
\text { Error }(\%)=100 \times \frac{\bar{d}_{\mathrm{RSA}}-\bar{d}_{\mathrm{NLRHA}}}{\bar{d}_{\mathrm{NLRHA}}},
$$

where $\bar{d}_{\text {RSA }}$ is the mean of the maximum displacement resulting from RSA, while $\bar{d}_{\mathrm{NLRHA}}$ is the mean of maximum displacement resulting from NLRHA. Since the slenderness $L_{x} / L_{y}$ of the building in plan is 3.26 , the torsional effects 


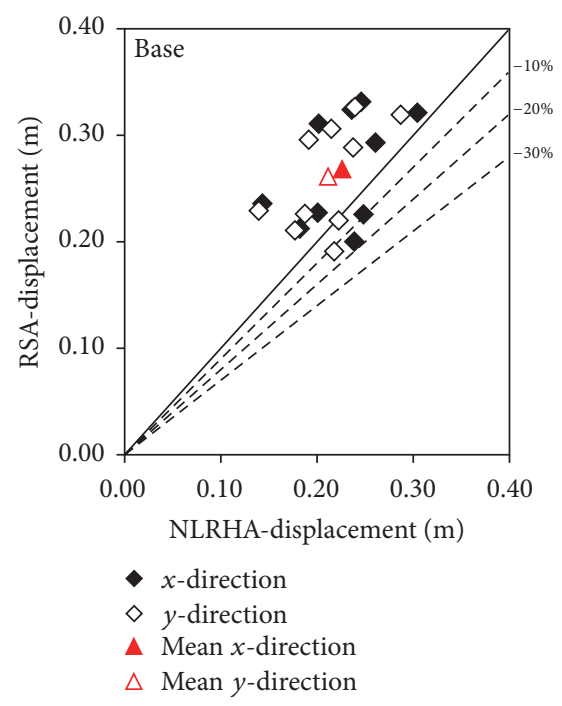

(a)

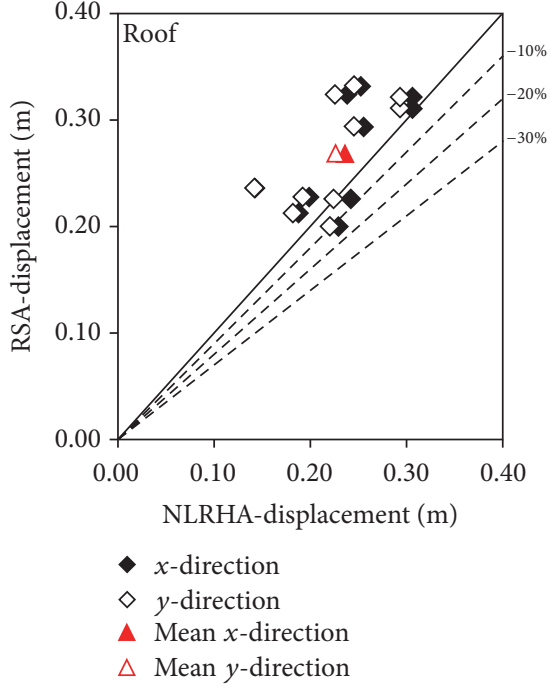

(b)

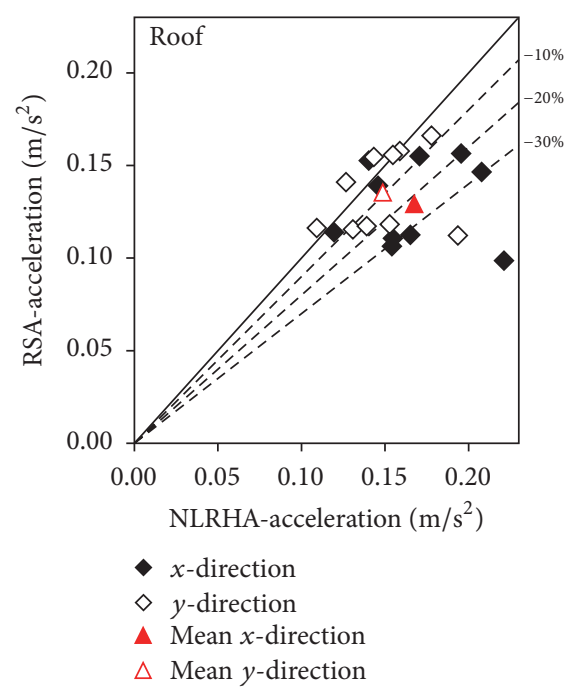

(c)

FIgURE 16: Scatter plot: (a) base displacement; (b) roof displacement; (c) roof acceleration.

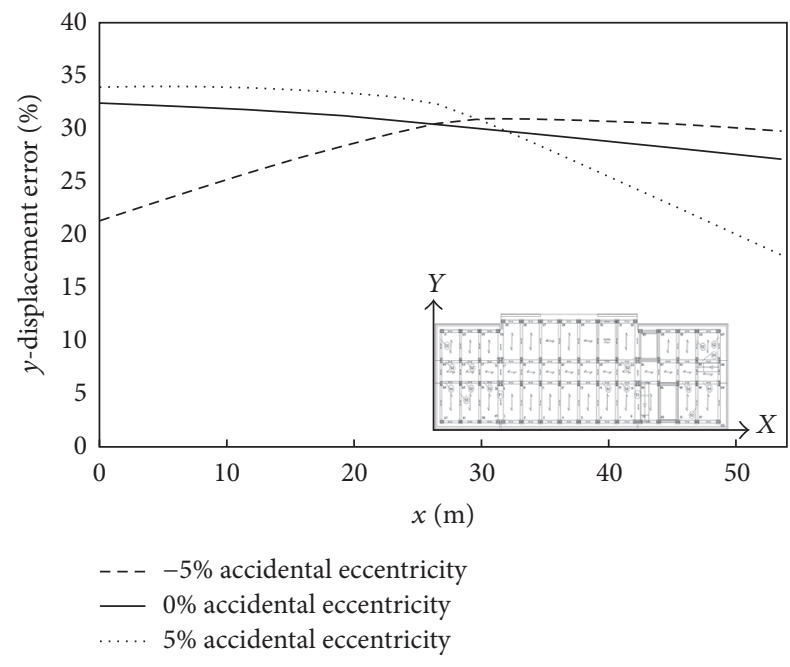

FIGURE 17: Distribution along $x$-axis of $y$-displacement error.

obtained for seismic action in the $y$-direction are greater than those calculated in the $x$-direction. In Figure 17, the distribution along the $x$-axis of the $y$-displacement error is plotted. This graph synthesizes the accuracy of RSA when used for the evaluation of $y$-displacement also in the presence of accidental eccentricity. The results show that the lateral displacements are, in general, underestimated, up to $34 \%$ on the flexible side.

The case study is composed of three different structures which are connected by the isolation plane at the ground floor but are disconnected by seismic separation gaps in elevation. In this situation, the possibility of poundings between the three superstructures, also due to the irregularity in plan, deserves to be investigated. Thus, the evaluation of the equivalent linear analysis method was carried out also considering the relative displacement between the superstructures in the direction of pounding (longitudinal $x$-direction). To this aim, the live loads were applied to maximize the torsional effects in the superstructure. The accuracy of RSA was evaluated in terms of relative $x$-displacement between the adjacent superstructures (A-B; B-C). In Figure 18, the displacement error of RSA respect to NRHA is plotted on the $x$-axis for different positions of potential pounding locations (plotted on the $y$-axis). The analyses were carried out for seismic action: (a) in the $x$-direction; (b) in the $y$-direction. The results indicate that the error is greater for seismic action in the direction of pounding ( $x$-direction). The relative displacements are underestimated up to $61.74 \%$. After all, the relative $x$-displacements between the three superstructure for seismic action in the direction of pounding ( $x$-direction) are expected to be more sensitive to higher mode effects. When these effects are significant, the equivalent linearization method tends to become inappropriate to evaluate the seismic pounding effects.

\section{Discussion}

Some of the results of the present paper can be generalized. It was found that the code specified equivalent linear elasticviscous damping model of the isolator underpredicts the superstructure acceleration (underestimation of $22.9 \%$ in $x$ direction and $-8.9 \%$ in $y$-direction) and overpredicts the bearing displacement (overestimation of $18.6 \%$ in $x$-direction and $23.6 \%$ in $y$-direction). This is a general result, valid also for other base-isolated constructions without a multiple building structure. The same results were found by Matsagar and Jangid [10] in the case of base-isolated building modelled as a shear type structure mounted on isolation systems with one lateral degree-of-freedom at each floor. In the same way, similar to other studies in the literature, it was found that increasing period of isolators results in large displacement 


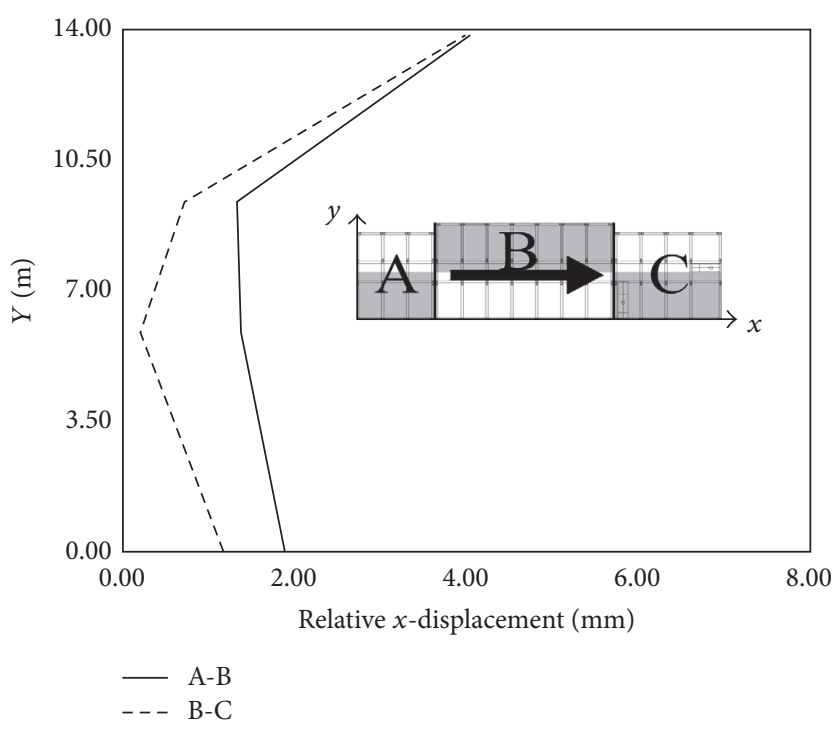

(a)

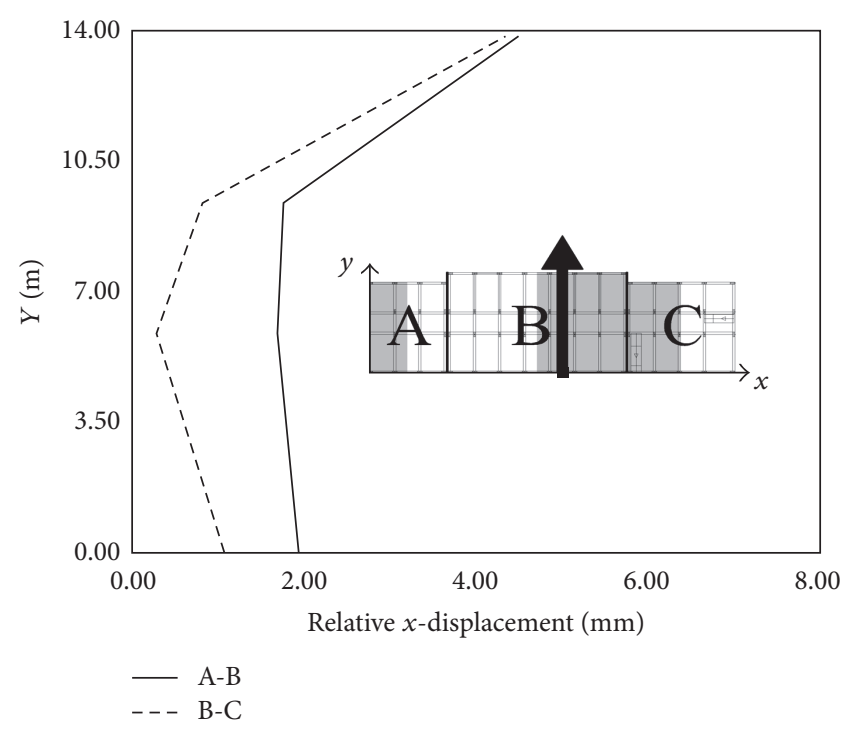

(b)

FIGURE 18: Relative $x$-displacement error. (a) Earthquake in $x$-direction. (b) Earthquake in $y$-direction.

at bearings on the flexible edge of the isolation system. The investigation about the suitability of the linearized elastic model for the analysis of the accidental torsional effects also showed that the lateral displacements are, in general, underestimated on the flexible side. The parametric analyses available in the literature $[8,17,18]$ reveal that the effective viscous damping ratio is one of the most important parameters that influences considerably the analysis. However, the effective viscous damping ratio that is required to match the inelastic response of the isolation bearings may be higher than the limiting value of $30 \%$, which is used as an upper bound by Eurocode 8 to use the linear elastic analysis for seismically isolated structures. Moreover, the estimation accuracy of the various equivalent linearization methods and corresponding parameters was found to be strongly dependent on the shape and parameters of the hysteresis loop of the isolator. Thus, the effective viscous damping ratio that best simulates a given hysteresis type may be inaccurate when applied to another hysteresis types. Other studies [9] showed that the accuracy of the equivalent linear analysis results is also affected by the peak ground acceleration to peak ground velocity ratio of the ground motion as well as the frequency content of the ground motion and the excitation intensity relative to the characteristic strength of the isolator. The same authors demonstrated that the effective damping equation currently used in the design of seismic-isolated structures should incorporate the effective period of the structure and frequency characteristics of the ground motion for a more accurate estimation of seismic response quantities. Liu et al. [18] proposed to modify the equivalent linear model recommended in codes through introducing a factor, which is related to ductility ratio, post-to-pre yield stiffness ratio, and initial period of seismic isolation system. The authors demonstrated that the newly proposed equivalent linear model produces more accurate results when compared with other equivalent linear models.
However, it should be observed that all the aforementioned proposals for modification of the equivalent linear model recommended in codes are generally based on a single base-isolated structure modelled as a single-degreeof-freedom system. Thus, they cannot be generalized to multiple building structures with specific issues regarding higher-modes and accidental torsional effects. On the other hand, the results of the case study reflect the difficulty to capture sufficiently well the actually nonlinear inelastic response with simplified linearized models when applied to $3 \mathrm{D}$ complex model of multiple building structure. The linear elastic analysis is, in general, conservative, regarding the estimation of the maximum relative displacements at the isolation level. Thus, it may be used, under certain limitations, in the preliminary design of a seismically isolated building. On the contrary, the design of the building using the linear elastic analysis would be inadequate for the seismic protection of sensitive equipment, since it underestimates the peak absolute floor acceleration. Moreover, the results indicate that the equivalent linearization method greatly underestimates both torsional and seismic pounding effects that are very important issues in design of multiple building structures. Thus, for the final analysis of these complex structures, the more accurate inelastic analysis should be used, which can be simply performed, currently, considering the significantly improved available computing resources.

\section{Conclusions}

This research work was needed to assess the accuracy of the expression adopted by standards for equivalent linearization when it is intended for multi-degree-of-freedom systems. The isolation system here considered satisfies the limited conditions of equivalent linearization specified in many codes by special requirements involving equivalent stiffness, 
equivalent damping ratio, and restoring force. However, the approximate linear methods were assessed based on a singledegree-of-freedom model, while general conclusions for real three-dimensional structures are still lacking. Moreover, the case study is a multiple building structure that is quite different from a single base-isolated structure, since both torsion and higher mode effects in the superstructure may be significant. The suitability of using a linearized elastic model for the analysis of a seismically isolated multiple building structure was investigated by comparing its calculated response with that computed by a more accurate inelastic model for the isolation system. To this aim, both nonlinear time-history analysis and nonlinear modal timehistory analysis were carried out. The fast nonlinear analysis was found to be an efficient integration scheme to perform nonlinear time-history analyses of base-isolated structures. Maximum displacement, acceleration, and interstorey drift averaged over ten ground motions were considered as evaluation indicators. Results revealed large discrepancies on the computed responses considering linearized elastic or Wen inelastic models for the rubber isolation bearings. In fact, the error on the mean value of the interstorey drift was found greater than $20 \%$ giving unconservative estimates of structural responses. The errors were very scattered without any specific tendency if the direction of the seismic action is perpendicular to the greater plan dimension, where torsional effects are more relevant. The effects of the accidental torsional eccentricity on the seismic behaviour of the multiple building structure were generally overestimated especially on the flexible side where the error is of about $34 \%$ in the worst case. The error on acceleration was greater than $20 \%$ giving a significant unconservative estimation of the seismic demand. In the same way, the relative displacement between the adjacent superstructures was underestimated (up to 61.74\%) when calculated with the equivalent linear analysis method, giving unrealistic predictions for design against earthquakeinduced pounding. The discrepancy of the results reported above reflects the difficulty in capturing sufficiently well the actually nonlinear inelastic response of base-isolated multiple building structures with simplified linearized models, even when the limited conditions of equivalent linearization are satisfied.

This preliminary study investigates the limitations of the equivalent linearization method when applied to a $3 \mathrm{D}$ complex model of a base-isolated multiple building structure. There are still many factors and uncertainties that need to be addressed. Firstly, the building represents a case study, even though particularly significant. Thus, the parametric analysis of various multistorey buildings for variations in the fundamental isolation period, damping, and isolation systems would be needed. Moreover, according to the current building codes the ground motion selection and scaling procedure simply compares their average to the target spectrum, without imposing limits on the scaling of individual ground motions. Thus, it may be significant to evaluate how to apply the scaling procedure for earthquake ground motions so that the results from response spectral analysis and time-history analysis are comparable. The damping correction factor, even though largely applied in the current seismic codes, may provide inaccurate predictions for seismically isolated buildings. Thus, the development of alternative procedures to estimate the damping correction factor to perform more accurate linear analysis may be a very interesting topic. Finally, for friction pendulum bearings the vertical ground motions effects may influence the seismic performance of the isolation system and thus needed to be investigated.

\section{Competing Interests}

The authors declare that they have no competing interests.

\section{Acknowledgments}

The authors express their personal appreciation to the valuable assistance given to them in the construction site by Fabio Formato and Alberto Maria Avossa (Design Engineers), Giovambattista Aquilino Musto (Construction Manager), Sergio Casarella (Testing Manager), and Vincenzo Botticelli (Technical Manager of MUCAFER Enterprise).

\section{References}

[1] A. R. Bhuiyan, Y. Okui, H. Mitamura, and T. Imai, "A rheology model of high damping rubber bearings for seismic analysis: identification of nonlinear viscosity," International Journal of Solids and Structures, vol. 46, no. 7-8, pp. 1778-1792, 2009.

[2] S. K. Jain and S. K. Thakkar, "Experimental investigations on laminated rubber bearings," Bulletin of Earthquake Engineering, vol. 3, no. 1, pp. 129-136, 2005.

[3] O. E. Ozbulut and S. Hurlebaus, "Evaluation of the performance of a sliding-type base isolation system with a NiTi shape memory alloy device considering temperature effects," Engineering Structures, vol. 32, no. 1, pp. 238-249, 2010.

[4] D. M. Fenz and M. C. Constantinou, "Behaviour of the double concave Friction Pendulum bearing," Earthquake Engineering \& Structural Dynamics, vol. 35, no. 11, pp. 1403-1424, 2006.

[5] Federal Emergency Management Agency, "Prestandard and commentary for the seismic rehabilitation of buildings," FEMA 356, American Society of Civil Engineers for the Federal Emergency Management Agency, Washington, DC, USA, 2000.

[6] Comité Européen de Normalisation CEN, Eurocode 8-Design Provisions for Earthquake Resistance of Structures, European Communities for Standardization, Brussels, Belgium, 2004.

[7] NTC 2008, Norme Tecniche per le Costruzioni, D.M. Infrastrutture Trasporti 14 gennaio 2008, 2008 (Italian).

[8] T. Zordan, T. Liu, B. Briseghella, and Q. Zhang, "Improved equivalent viscous damping model for base-isolated structures with lead rubber bearings," Engineering Structures, vol. 75, pp. 340-352, 2014.

[9] M. Dicleli and S. Buddaram, "Comprehensive evaluation of equivalent linear analysis method for seismic-isolated structures represented by sdof systems," Engineering Structures, vol. 29, no. 8, pp. 1653-1663, 2007.

[10] V. A. Matsagar and R. S. Jangid, "Influence of isolator characteristics on the response of base-isolated structures," Engineering Structures, vol. 26, no. 12, pp. 1735-1749, 2004.

[11] J. S. Hwang, J. D. Wu, T.-C. Pan, and G. Yang, "A mathematical hysteretic model for elastomeric isolation bearings," Earthquake 
Engineering \& Structural Dynamics, vol. 31, no. 4, pp. 771-789, 2002.

[12] M. Jara, J. M. Jara, B. A. Olmos, and J. R. Casas, "Improved procedure for equivalent linearization of bridges supported on hysteretic isolators," Engineering Structures, vol. 35, pp. 99-106, 2012.

[13] E. Rosenblueth and I. Herrera, "On a kind of hysteretic damping," Journal of Engineering Mechanics (ASCE), vol. 90, no. 4, pp. 37-48, 1964.

[14] AASHTO, Guide Specifications for Seismic Isolation Design, American Association of State Highway and Transportation Officials, Washington, DC, USA, 2002.

[15] E. Mavronicola and P. Komodromos, "Assessing the suitability of equivalent linear elastic analysis of seismically isolated multistorey buildings," Computers and Structures, vol. 89, no. 21-22, pp. 1920-1931, 2011.

[16] D. R. Pant, M. C. Constantinou, and A. C. Wijeyewickrema, "Re-evaluation of equivalent lateral force procedure for prediction of displacement demand in seismically isolated structures," Engineering Structures, vol. 52, pp. 455-465, 2013.

[17] T. Liu, T. Zordan, B. Briseghella, and Q. Zhang, "Evaluation of equivalent linearization analysis methods for seismically isolated buildings characterized by SDOF systems," Engineering Structures, vol. 59, pp. 619-634, 2014.

[18] T. Liu, T. Zordan, B. Briseghella, and Q. Zhang, "An improved equivalent linear model of seismic isolation system with bilinear behaviour," Engineering Structures, vol. 61, pp. 113-126, 2014.

[19] Y.-Y. Lin, E. Miranda, and K.-C. Chang, "Evaluation of damping reduction factors for estimating elastic response of structures with high damping," Earthquake Engineering and Structural Dynamics, vol. 34, no. 11, pp. 1427-1443, 2005.

[20] R. Weitzmann, M. Ohsaki, and M. Nakashima, "Simplified methods for design of base-isolated structures in the longperiod high-damping range," Earthquake Engineering and Structural Dynamics, vol. 35, no. 4, pp. 497-515, 2006.

[21] G. Muscolino, A. Palmeri, and C. Versaci, "Damping-adjusted combination rule for the response spectrum analysis of baseisolated buildings," Earthquake Engineering and Structural Dynamics, vol. 42, no. 2, pp. 163-182, 2013.

[22] P. Malangone and M. Ferraioli, "A modal procedure for seismic analysis of non-linear base-isolated multistorey structures," Earthquake Engineering and Structural Dynamics, vol. 27, no. 4, pp. 397-412, 1998.

[23] Uniform Building Code, International Conference of Building Officials, UBC, Whittier, Calif, USA, 1997.

[24] P. Leger, E. L. Wilson, and R. W. Clough, "The use of load dependent vectors for dynamic and earthquake analyses," Report UCB/EERC-86/04, Berkeley University, 1986.

[25] M. Ferraioli, A. Lavino, and A. Mandara, "Behaviour factor of code-designed steel moment-resisting frames," International Journal of Steel Structures, vol. 14, no. 2, pp. 243-254, 2014.

[26] M. Ferraioli, A. M. Avossa, A. Lavino, and A. Mandara, "Accuracy of advanced methods for nonlinear static analysis of steel moment-resisting frames," Open Construction and Building Technology Journal, vol. 8, pp. 310-323, 2014.

[27] M. Ferraioli, "Dynamic increase factor for pushdown analysis of seismically designed steel moment-resisting frames," International Journal of Steel Structures, vol. 16, no. 3, pp. 857-875, 2016.

[28] M. Ferraioli, A. M. Avossa, and F. Formato, "Base isolation seismic retrofit of a hospital building in Italy: design and construction," in COST ACTION C26: Urban Habitat Constructions under Catastrophic Events-Proceedings of the Final Conference, pp. 835-840, 2010.

[29] M. Ferraioli, R. Costanzo, and A. Lavino, "Base isolation seismic retrofit of a hospital building in Italy: performance under earthquake strong ground motions," in Proceedings of the Final Conference on COST Action C26: Urban Habitat Constructions under Catastrophic Events, pp. 841-846, Naples, Italy, September 2010.

[30] Y.-K. Wen, "Method for random vibration of hysteretic systems," ASCE Journal of the Engineering Mechanics, vol. 102, no. 2, pp. 249-263, 1976.

[31] F. Ikhouane, J. E. Hurtado, and J. Rodellar, "Variation of the hysteresis loop with the Bouc-Wen model parameters," Nonlinear Dynamics, vol. 48, no. 4, pp. 361-380, 2007.

[32] H.-G. Li and G. Meng, "Nonlinear dynamics of a SDOF oscillator with Bouc-Wen hysteresis," Chaos, Solitons and Fractals, vol. 34, no. 2, pp. 337-343, 2007.

[33] M. Ferraioli and P. Malangone, "Nonlinear modeling for dynamic analysis of base-isolated structures," in Proceedings of the 11th European Conference on Earthquake Engineering, Paris, France, 1997.

[34] CSI Computer \& Structures Inc. SAP2000, Linear and Nonlinear Static and Dynamic Analysis of Three-Dimensional Structures, CSI Computer \& Structures, Berkeley, Calif, USA, 2015.

[35] J. B. Mander, M. J. N. Priestley, and R. Park, "Theoretical stressstrain model for confined concrete," Journal of Structural Engineering, vol. 114, no. 8, pp. 1804-1826, 1988.

[36] C. B. Haselton, J. W. Baker, A. B. Liel, and G. G. Deierlein, "Accounting for ground-motion spectral shape characteristics in structural collapse assessment through an adjustment for epsilon," Journal of Structural Engineering, vol. 137, no. 3, pp. 332-344, 2011.

[37] E. I. Katsanos, A. G. Sextos, and G. D. Manolis, "Selection of earthquake ground motion records: a state-of-the-art review from a structural engineering perspective," Soil Dynamics and Earthquake Engineering, vol. 30, no. 4, pp. 157-169, 2010.

[38] NIST, "Selecting and scaling earthquake ground motions for performing response history analyses," Tech. Rep. NIST GCR 11-917-15, NEHRP Consultants Joint Venture for the National Institute of Standards and Technology, Gaithersburg, Md, USA, 2011.

[39] J. Hancock, J. A. Watson-Lamprey, N. A. Abrahamson et al., "An improved method of matching response spectra of recorded earthquake ground motion using wavelets," Journal of Earthquake Engineering, vol. 10, no. 1, pp. 67-89, 2006.

[40] H. Thráinsson and A. S. Kiremidjian, "Simulation of digital earthquake accelerograms using the inverse discrete Fourier transform," Earthquake Engineering and Structural Dynamics, vol. 31, no. 12, pp. 2023-2048, 2002.

[41] Y. C. Kurama and K. T. Farrow, "Ground motion scaling methods for different site conditions and structure characteristics," Earthquake Engineering and Structural Dynamics, vol. 32, no. 15, pp. 2425-2450, 2003.

[42] K. Beyer and J. J. Bommer, "Selection and scaling of real accelerograms for bi-directional loading: a review of current practice and code provisions," Journal of Earthquake Engineering, vol. 11, no. 1, pp. 13-45, 2007.

[43] J. W. Baker and C. A. Cornell, "Spectral shape, epsilon and record selection," Earthquake Engineering and Structural Dynamics, vol. 35, no. 9, pp. 1077-1095, 2006.

[44] J. C. Reyes and A. K. Chopra, "Modal pushover-based scaling of two components of ground motion records for nonlinear RHA 
of structures," Earthquake Spectra, vol. 28, no. 3, pp. 1243-1267, 2012.

[45] J. W. Baker, "Conditional mean spectrum: tool for groundmotion selection," Journal of Structural Engineering, vol. 137, no. 3, pp. 322-331, 2011.

[46] J. Watson-Lamprey and N. Abrahamson, "Selection of ground motion time series and limits on scaling," Soil Dynamics and Earthquake Engineering, vol. 26, no. 5, pp. 477-482, 2006.

[47] International Code Council (ICC), International Building Code, IBC 2009, Country Club Hills, Ill, USA, 2009.

[48] American Society of Civil Engineers (ASCE), "Minimum design loads for buildings and other structures," ASCE 7-05, 2006.

[49] N. Ambraseys, P. Smit, R. Berardi, D. Rinaldis, F. Cotton, and C. Berge-Thierry, Dissemination of European Strongmotion Data (Cd-Rom Collection), European Council, Environment and Climate Research Programme, Brussels, Belgium, 2000.

[50] Building Seismic Safety Council (BSSC), "NEHRP Recommended Seismic Provisions for New Buildings and Other Structures," FEMA P750, Building Seismic Safety Council (BSSC), Washington, DC, USA, 2009.

[51] A. Tena-Colunga and J. L. Escamilla-Cruz, "Torsional amplifications in asymmetric base-isolated structures," Engineering Structures, vol. 29, no. 2, pp. 237-247, 2007.

[52] M. Ferraioli, "Case study of seismic performance assessment of irregular RC buildings: hospital structure of Avezzano (L'Aquila, Italy)," Earthquake Engineering and Engineering Vibration, vol. 14, no. 1, pp. 141-156, 2015.

[53] M. Ferraioli, "Inelastic torsional response of an asymmetricplan hospital building in Italy," in Proceedings of the Final Conference on COST Action C26: Urban Habitat Constructions under Catastrophic Events, pp. 365-370, Naples, Italy, September 2010.

[54] M. Ferraioli, D. Abruzzese, L. Miccoli, A. Vari, and G. Di Lauro, "Structural identification from environmental vibration testing of an asymmetric-plan hospital building in Italy," in Proceedings of the Final Conference on COST ACTION C26: Urban Habitat Constructions under Catastrophic Events, pp. 981-986, 2010. 


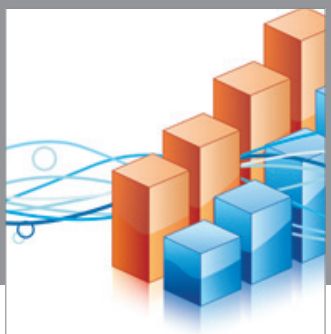

Advances in

Operations Research

vatem alat4

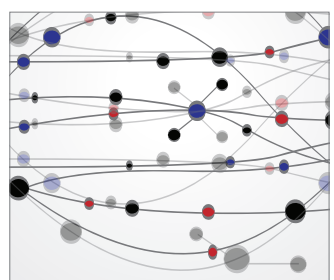

\section{The Scientific} World Journal
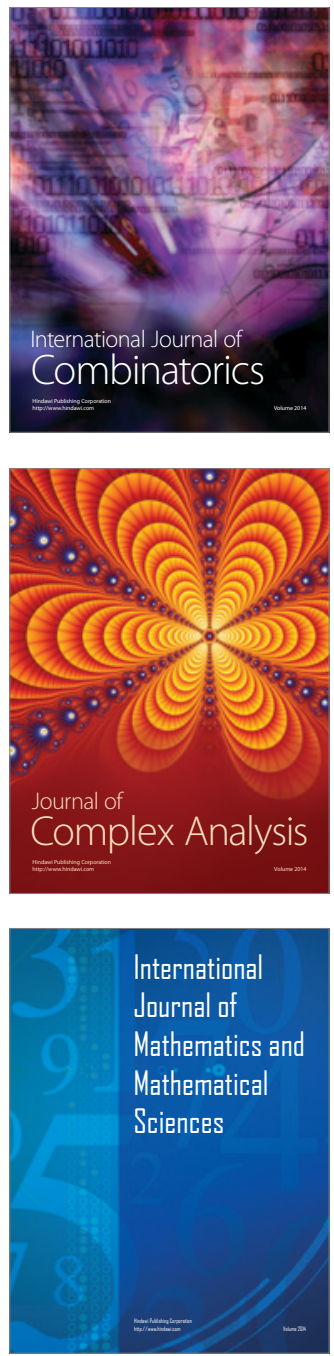
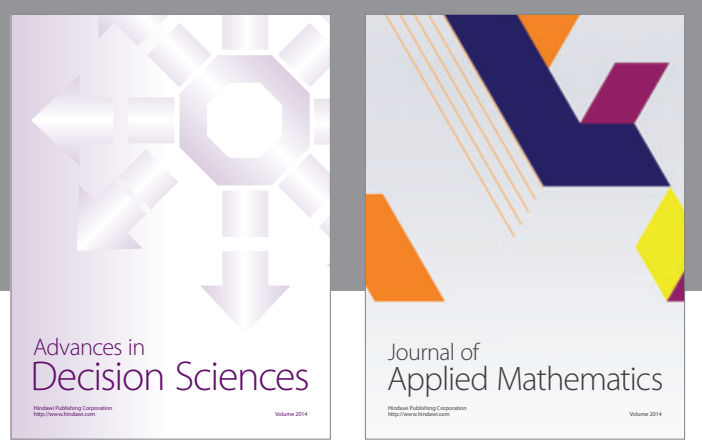

Algebra

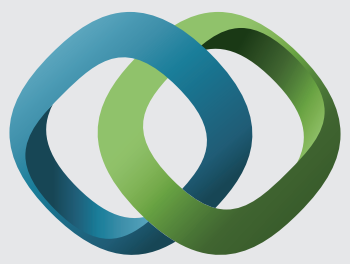

\section{Hindawi}

Submit your manuscripts at

http://www.hindawi.com
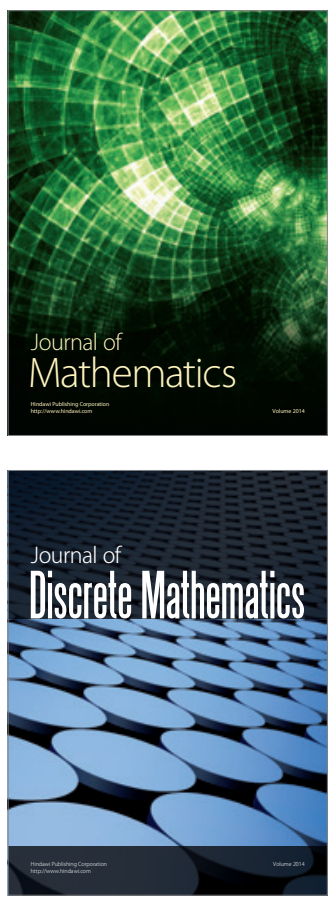

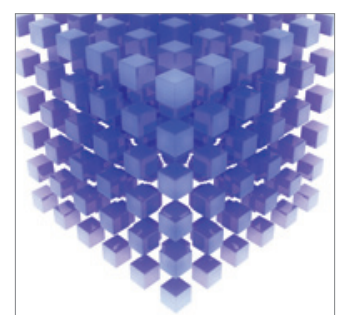

Mathematical Problems in Engineering
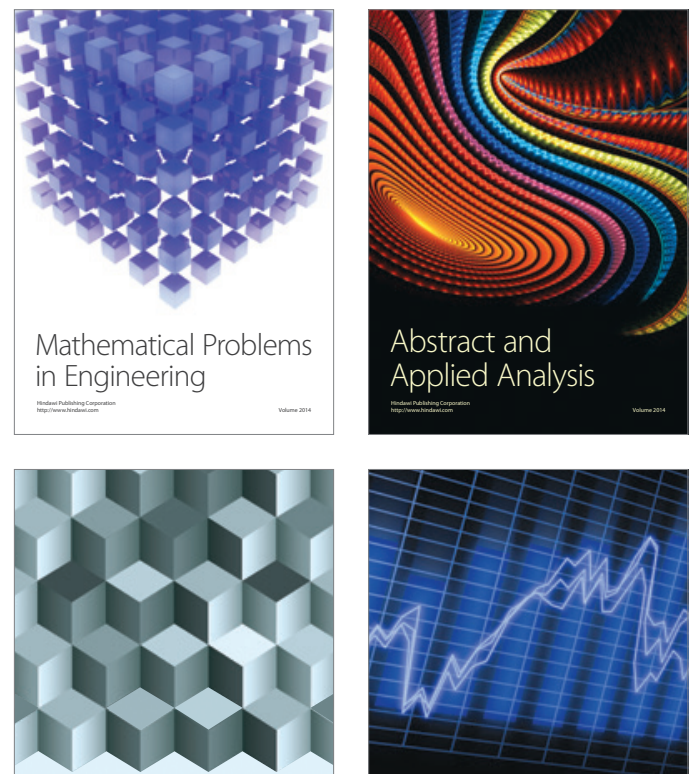

Journal of

Function Spaces

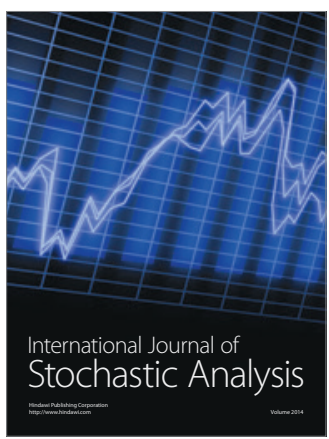

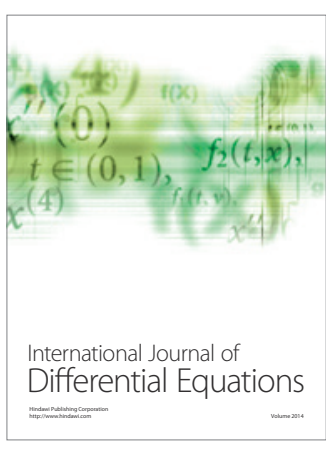
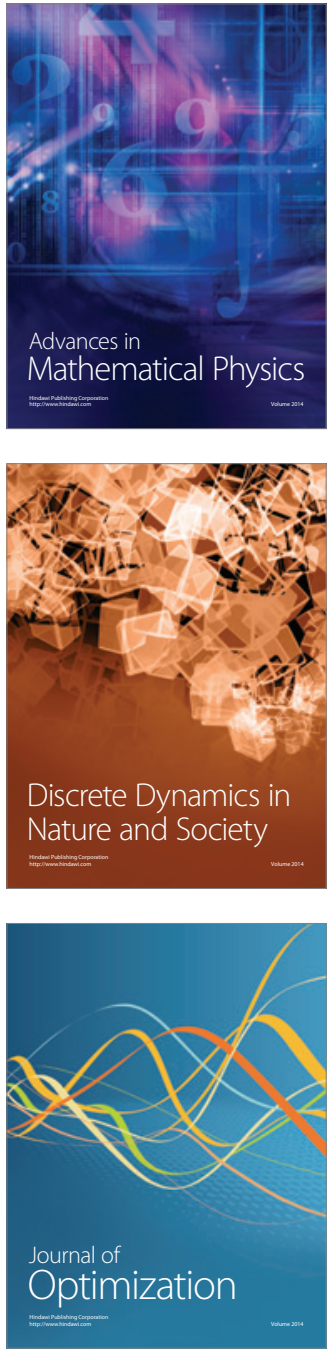